SAND90-1178

DE91 002580

TTC-0974

Unlimited Release

Printed August 1990

\title{
DEVELOPMENT AND TEST CASE APPLICATION OF A WASTE MINIMIZATION PROTECT EVALUATION METHOD
}

\author{
Edwin A. Kjeldgaard \\ P. O. Box 5800 \\ Risk Assessment and Transportation Division 6321 \\ Sandia National Laboratories \\ Albuquerque, New Mexico 87185 \\ and \\ Jose H. Saloio \\ G. Bruce Varnado \\ ERC Environmental and Energy Services Company \\ 7301A Indian School Road NE \\ Albuquerque, New Mexico 87110
}

\begin{abstract}
The authors have developed and applied a methodology to evaluate and prioritize proposed waste minimization activities affecting Department of Energy (DOE) programs. This approach provides a systematic and defensible method for selecting a set of waste minimization proposals that maximizes the benefits to DOE while maintaining costs within a specified budget. The report discusses the development of a structured set of evaluation criteria to characterize waste minimization issues; techniques for documenting the anticipated and potential costs, risks, and benefits of waste minimization proposals; and a method of translating disparate data into a figure of merit for each proposal. A test case demonstration of this prioritization approach was applied to proposals currently being considered at two DOE weapons production facilities. Recommendations are provided for combining this approach with the existing DOE proposal selection process.
\end{abstract}

\section{iii/iv}




\section{CONTENTS}

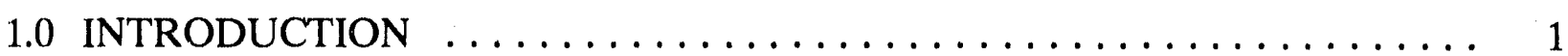

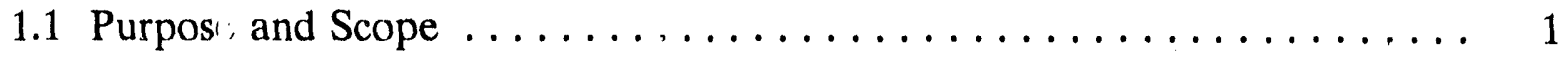

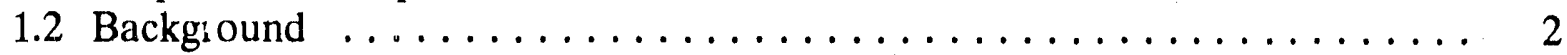

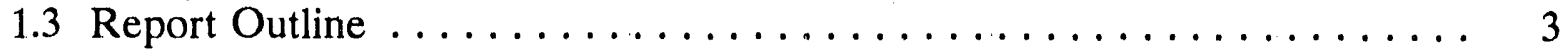

2.0 EVALUATION AND PRIORITIZATION METHODOLOGY $\ldots \ldots \ldots \ldots$

2.1 Evaluation Criteria Development $\ldots \ldots \ldots \ldots \ldots \ldots$

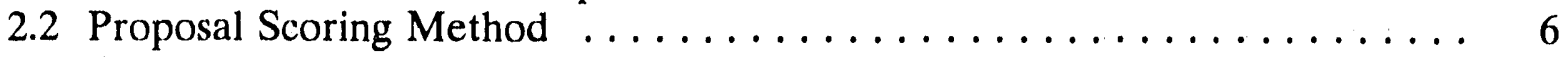

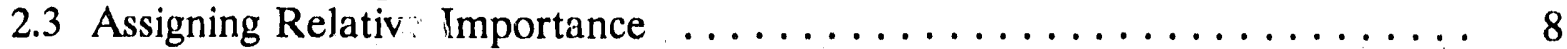

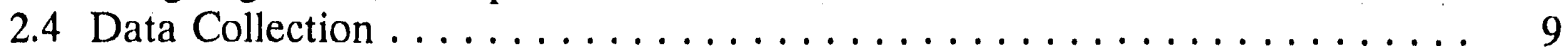

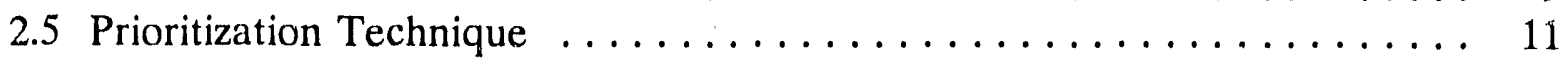

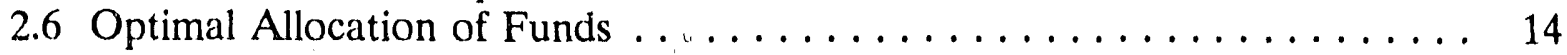

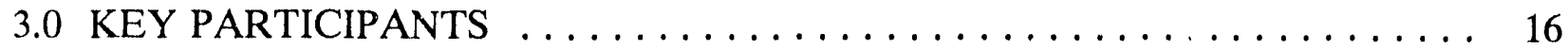

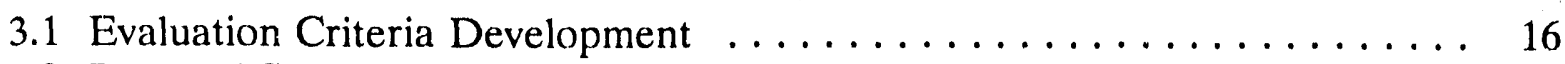

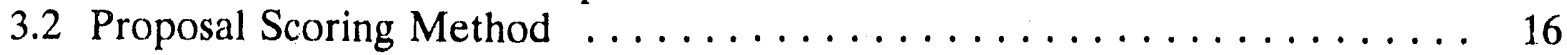

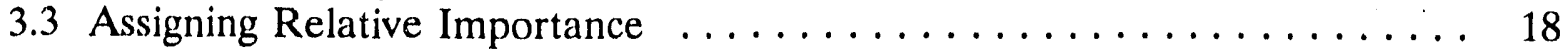

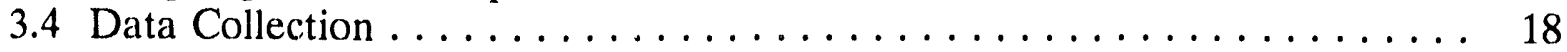

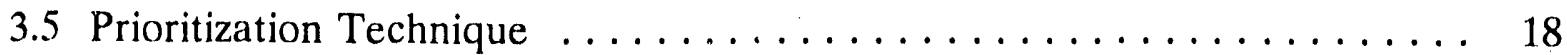

3.6 Optimal Allocation of Funds . . . . . . . . . . . . . . . . . . . . 19

4.0 PROPOSED WASTE MINIMIZATION PROJECTS . . . . . . . . . . . . . . . 19

4.1 Rocky Flats Test Case Study -- Reservoir Rinsing . . . . . . . . . . . . . . 19

4.1.1 Description of Waste Minimization Process Change . . . . . . . . . 19

4.1.2 Anticipated Benefits, Risks, and Costs . . . . . . . . . . . . 20

4.2 Pinellas Test Case Study -. Magnetic Component Potting . . . . . . . . . . . 22

4.2.1 Description of Waste Minimization Process Change . . . . . . . . 22

4.2.2 Anticipated Benefits, Risks, and Costs . . . . . . . . . . . . 23

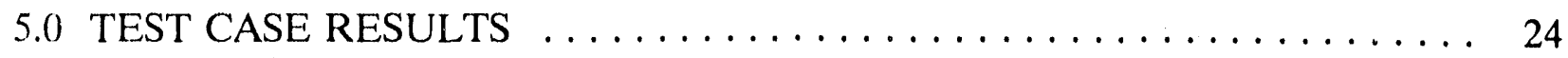

6.) CONCLUSIONS AND RECOMMENDATIONS . . . . . . . . . . . 31

REFERENCES ............................. 35 


\section{CONTENTS (Continued)}

APPENDIX A Evaluation Criteria for Waste Minimization Proposals $\ldots \ldots \ldots$ A-1 APPENDIX B Summary Findings for Waste Minimization Proposals ........ B-1 APPENDIX C Summary Findings For Rocky Flats Plant Test Case Study . . . . . C-1 APPENDIX D Summary Findings For Pinellas Plant Test Case Study $\ldots \ldots \ldots$ D.1 


\section{FIGURES}

2-1. Evaluation and Prioritization Process $\ldots \ldots \ldots \ldots \ldots \ldots \ldots \ldots, \ldots \ldots \ldots$

2-2. Silbset of Evaluation Criteria Used in Test Case .............. 5

2-3. Example Summary Findings Used in Test Case $\ldots \ldots \ldots \ldots \ldots \ldots \ldots \ldots$

2-4. Example Worksheet for Data Collection ................... 12

2-5. Final Score Computation $\ldots \ldots \ldots \ldots \ldots \ldots \ldots \ldots \ldots \ldots \ldots \ldots \ldots$

3-1. Evaluation and Prioritization Process and Key Participants $\ldots \ldots \ldots \ldots \ldots 17$

5-1. Completed Summary Findings $\ldots \ldots \ldots \ldots \ldots \ldots \ldots \ldots \ldots \ldots \ldots \ldots$

5-2. Rocky Flats Acid Elimination Proposal $\ldots \ldots \ldots \ldots \ldots \ldots \ldots \ldots \ldots . \ldots . \ldots . \ldots 27$

5-3. Pinellas Shell Z Substitution Proposal $\ldots \ldots \ldots \ldots \ldots \ldots \ldots \ldots \ldots \ldots$

\section{TABLES}

2-1. Types of Data Collected in Test Case $\ldots \ldots \ldots \ldots \ldots \ldots \ldots \ldots \ldots \ldots$

5-1. Numerical Representation of Final Scores and Top-Level Evaluation Criteria Scores .................................

5-2. Graphical Representation of Final Scores and Top-Level Evaluation Criteria

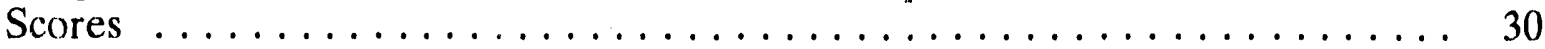




\subsection{INTRODUCTION}

\subsection{Purpose and Scope}

The purpose of this report is to describe a formal process for selecting, from a large and diverse set of proposed waste minimization activities, those activities that provide the greatest benefit to the U.S. Department of Energy (DOE). The objectives of the effort described in this report are:

1. To develop a methodology for evaluating and prioritizing proposed waste minimization activities, and

2. To demonstrate this methodology in a "test case" on a small set of proposed activities.

The evaluation and prioritization methodology was developed to illustrate how this proposal selection process will work, what types of data are necessary to thoroughly characterize waste minimization activities, and who should participate in the process. Although the process was developed specifically for waste minimization proposals, the methodology is generally applicable to many other prioritization issues confronting DOE (e.g., environmental restoration, facility modernization, etc.).

The DOE Office of Technology Development (OTD) sponsored this work as part of the DOE Cost Model and Risk/Benefit Analysis Workshop held in Albuquerque, New Mexico on March 27 and 28,1990 . The goal of the workshop was to assemble DOE policy makers, environmental planners, and systems analysts to begin the development of "a model that could be used to determine the cost of projects, associated risks/benefits, and could be simply applied. . . for partially prioritizing the projects that will be funded by [OTD]."1 ${ }^{1}$ The evaluation and prioritization methodology and the test case demonstration were presented at the workshop as a possible approach to supplement the existing OTD funding process. The results were critically reviewed by the workshop participants and many of their suggested, improvements have been incorporated in this report.

In the test case demonstration, the methodology was applied to ongoing waste minimization process changes within the DOE nuclear weapons complex. These projects illustrate the issues associated with modifying manufacturing processes to accommodate waste minimization initiatives and have costs, risks, and benefits that could be characterized relatively easily. (The status of the waste minimization activities, whether proposed or partially implemented, does not affect the application of the evaluation and prioritization methodology. The methodology was designed specifically to accommodate waste minimization activities in all phases of implementation.)

It is impossible to replace the judgment of experienced technical, financial, and policy personnel in a proposal selection process. Any credible attempt at comparing the uncertain possibilities of different proposals must always be based on

1 Frank, Clyde (DOE). Letter to Joan Woodard, Sandia National Laboratories (SNL), February 2, 1990. 
informed opinions and foresight. The arbitrary nature of this evaluation process can be reduced by improving the data describing each proposal, applying a consistent set of rules to measure proposal characteristics, and using rigorous mathematical techniques to compare proposals. However, even these logical constructs require subjective inputs. For these reasons, the ultimate aim of this report is to present an evaluation and prioritization methodology that will support (not replace) the traditional proposal selection process followed by DOE.

\subsection{Background}

Waste minimization activities at DOE facilities have increased significantly since the promulgation of DOE Order 5400.1, General Environmental Protection Program, and its implementation guidance (DOE, 1988a and 1988b). In addition to establishing requirements for reporting, training, and goal setting, DOE Order 5400.1 calls for increased emphasis on technology development for waste minimization. This call for technology development is echoed in the DOE Environmental Restoration and Waste Management Five-Year Plan and the subsequent Applied Research, Development, Demonstration, Testing and Evaluation Plan (DOE, 1989a and 1989b).

As a result of this heightened emphasis on waste minimization, OTD (the DOE office responsible for applied research and development programs) has received a large number of proposals from the operating facilities. Collectively, these proposals seek funding that exceeds the OTD budget. The large number und diversity of proposals that OTD must evaluate and prioritize increases the complexity of the proposal evaluation process.

The existing DOE funding process begins with the operating facilities submitting proposals to the appropriate DOE field office. Proposals describe the anticipated benefits of the project and the budget required for its implementation. Proposals are generally qualitative in nature (except for budget estimates) and are often returned to the operating facilities for additional information or clarification. The proposals are compared and evaluated by DOE headquarters staff using subjective judgment and are prioritized for funding purposes based on the perceived value of each proposal with respect to the agency's objectives. This system of evaluation and prioritization has become difficult to manage and defend because of the large number of proposals that are submitted to DOE each year. For example, OTD evaluated over 1000 proposals for fiscal year 1990 (FY90). ${ }^{2}$

With these issues in mind, Sandia National Laboratories (SNL) has developed and demonstrated an enhanced proposal evaluation and prioritization process that can support DOE funding decisions. The evaluation and prioritization process outlined in this report provides a defensible, auditable, and consistent method for selecting those waste minimization proposals that maximize the benefits to DOE while maintaining costs within the agency budget. Additicnally,

2 Vannoni, Michael (SNL). Telephone conversation with author, March 19, 1990. 
this process will focus and improve the dialogue among waste minimization activity proposers, evaluators, and decision makers.

\subsection{Report Outline}

This report contains five major sections including this Introduction. Section 2.0 describes the methodology that was developed to evaluate and prioritize a set of proposed waste minimization activities. Section 3.0 discusses the individuals and groups that should participate in the evaluation and prioritization process. Section 4.0 presents the proposed process changes that were analyzed in the test case, and Section 5.0 describes the test case results. Insights and conclusions from the project, along with recommendations for the future application and refinement of the methodology, are discussed in Section 6.0. Appendices A and B contain supporting materials that were developed as part of the evaluation and prioritization process. Appendices $C$ and D present the data describing the test case proposals.

\subsection{EVALUATION AND PRIORITIZATION METHODOLOGY}

This section presents the methodology that was developed to evaluate and prioritize waste minimization proposals. Six major steps constitute the overall evaluation and prioritization process:

1. Develop the evaluation criteria,

2. Develop a project scoring method,
3. Assign relative importance to the evaluation criteria and the scoring method,

4. Collect the proposal data,

5. Apply a prioritization technique, and

6. Optimize the allocation of funds to maximize the cumulative benefit.

Figure 2-1 illustrates how the major steps in the methodology are interrelated. Although these steps are described in this section in general terms, some references to the test case proposals are made to clarify concepts.

\subsection{Evaluation Criteria Development}

Evaluation criteria provide a means for organizing the various types of information cescribing proposed waste minimization activities. The criteria are organized in a hierarchy with the top-level criteria providing broad, logical groupings. These criteria are subdivided into lower-level criteria that have more focused areas of interest (see Figure 2-2). Criteria are successively subdivided until a level is reached where individual answers from the data collecilon process ran be introduced into the hierarchy through the proposal scoring method.

Five top-level evaluation criteria were used in the test case (listed in arbitrary order):

- Economic Feasibility,

- Effect on Environmental, Safety, and Health Issues, 


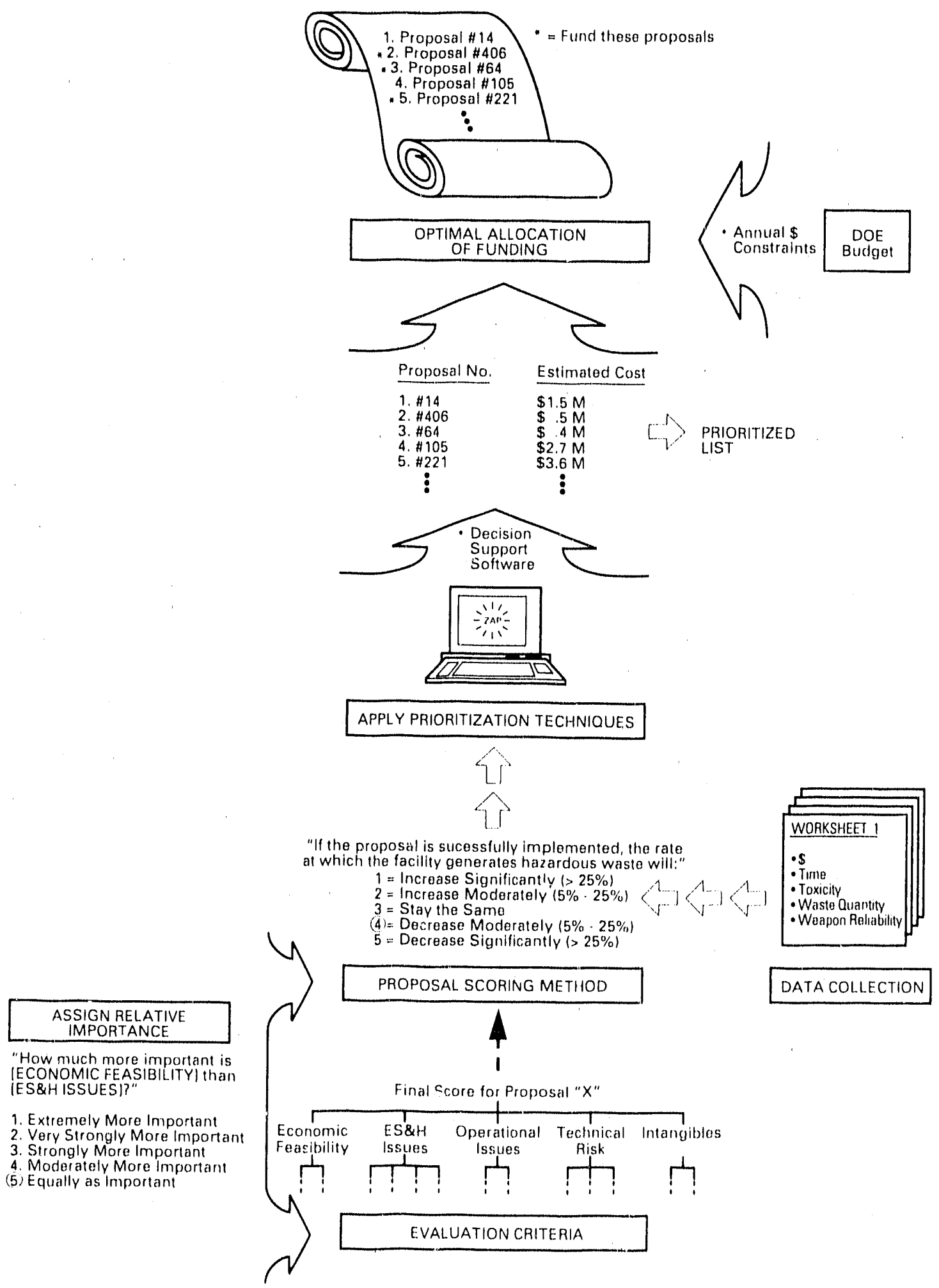

Figure 2-1. Evaluation and Prioritization Process 


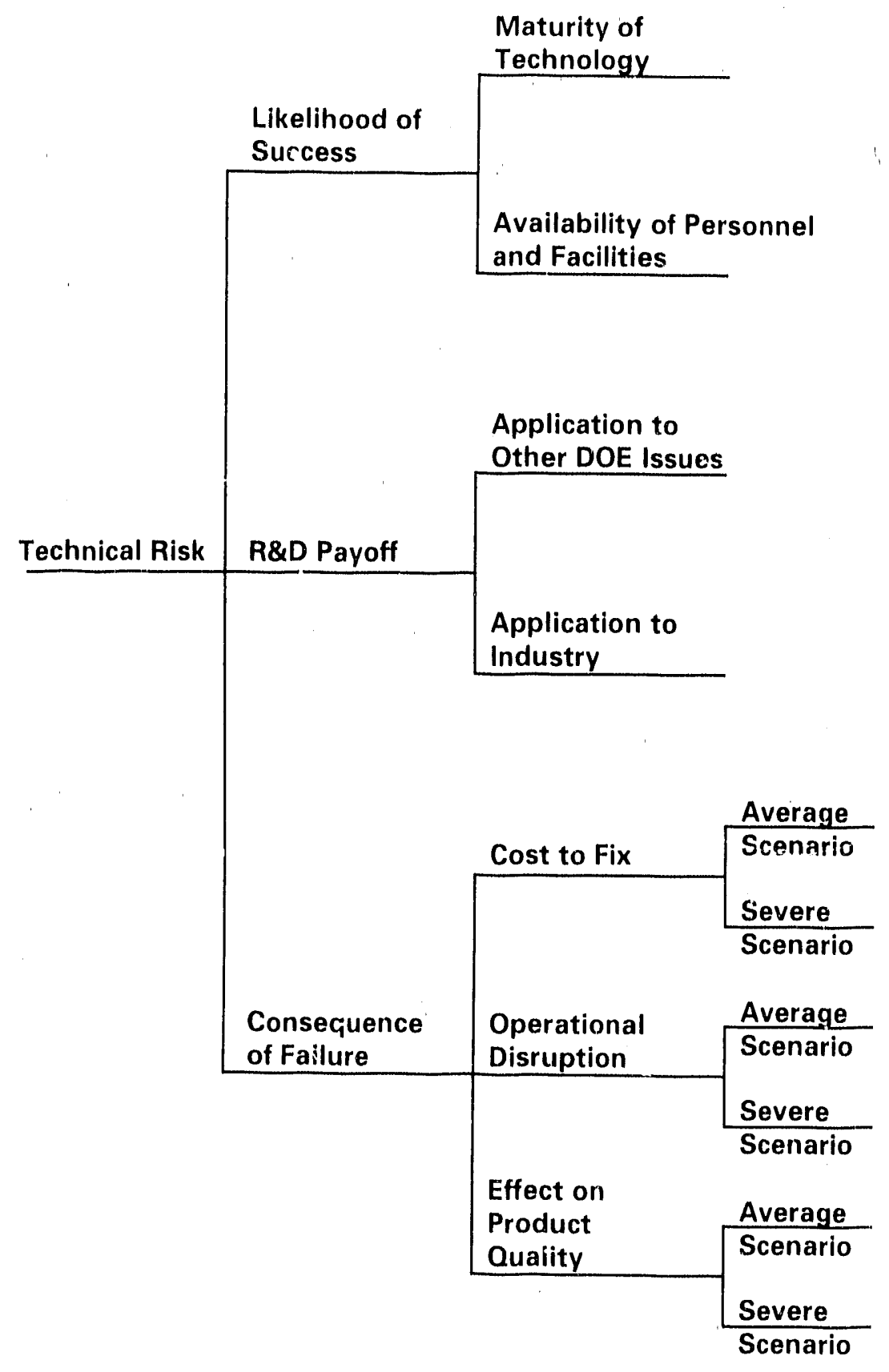

Figure 2-2. Subset of Evaluation Criteria Used in Test Case 
- Effect on Operational Issues,

- Effect on Intangibles, and

- Technical Risk.

Three or four levels of more detailed criteria were developed under each toplevel criterion. (Appendix A presents a complete outline of the evaluation criteria that were developed for the test case, plus additional criteria suggested by the attendees of the DOE Cost Model and Risk/Benefit Analysis Workshop.). We believe that these criteria represent the major factors by which proposed waste minimization activities can be systematically judged. Although the toplevel criteria may also be applicable to other technolngy areas (e.g., groundwater contamination, waste segregation, etc.), different lower-level criteria must be developed in order to apply the overall evaluation and prioritization method to other issues.

\subsection{Proposal Scoring Method}

One of the difficulties in comparing a diverse group of proposed activities is translating data describing each proposal into common units so that rational comparisons can be made. Furthermore, if a scale does not exist to measure the "good" or "bad" that will result from a proposal's implementation, judgments about its value must be made in an arbitrary manner. The proposal scoring method addresses these issues and provides a defensible method for translating both quantitative and qualitative data into comparable units. This method also provides a way to measure the positive and negative characteristics of a proposal.
"Summary findings" are used to measure each proposal with respect to the evaluation criteria. Summary findings are declarative statements about the lowestlevel (terminal) evaluation criteria used to characterize a proposal. For example, if a terminal criterion addresses worker exposure to hazardous material, a summary finding is developed and applied consistently to all proposals to measure worker exposure to hazardous material. A summary finding is developed for every terminal evaluation criterion in the hierarchy. Figure 2-3 presents an example of the summary findings used in the test case. (The fifty summary findings that were applied in the test case are presented in Appendix B.)

Responses to the summary findings (represented by whole number scores ranging from "1" to "5") are selected based on direct reference to specific quantitative data or a subjective interpretation of many different data items collected about a proposal. In all cases, the response "1" represents the worst possible outcome and "5" represents the best. Summary finding responses inat rely solely on quantitative data are completed in a straightforward manner. For example, a summary finding dealing with the anticipated time required to implement a proposed waste minimization activity relies only on the direct, quantitative information collected about implementation time. The only subjectivity present in this type of summary finding is the range of values attributed to each response (e.g., $5=$ less than 1 year, $1=$ greater than 10 years, etc.). In the test case, the demarcation between responses is based on the opinions of the authors. 
If the proposal is successfully implemented:

The number of workers exposed to hazardous material and waste during normal operations will:

$1=$ increase significantly

$2=$ increase slightly

$3=$ stay the same (not applicable)

$4=$ decrease slightly

$5=$ decrease significantly

The total length of time required to complete all phases of the proposal will be:

$1=$ greater than 10 years

$2=6$ to 10 years

$3=3$ to 6 years

$4=1$ to 3 years

$5=$ less than 1 year

The reliability of the ultimate product(s) provided by the DOE facilities involved in the proposal will:

$1=$ decrease significantly

$2=$ decrease slightly

$3=$ stay the same (not applicable)

$4=$ increase slightly

$5=$ increase significantly

Figure 2-3. Example Summary Findings Used in Test Case 
Qualitatively-based summary findings, however, require a more subjective interpretation. For example, a summary finding dealing with the long-term reliability of a weapon component is extremely difficult to characterize quantitatively. Instead of attempting to resnond quantitatively to this type of summary finding, the following five subjective responses were typically used for interpretations: $5=$ increase significantly, $4=$ increase slightly, $3=$ no effect, $2=$ decrease slightly, and $1=$ decrease significantly. In the test case, the authors' subjective interpretations of the collected data were the basis for selecting an appropriate response to qualitative summary findings.

\subsection{Assigning Relative Importance}

Evaluation criteria and summary findings must be prioritized so that some attributes of proposals receive more importance than others. A decision maker addressing this issue must state clearly ordinal preferences for particular evaluation criteria and possible summary finding responses. (Ordinal preference refers to establishing the ranked order of importance for the evaluation criteria and summary finding responses.) For example, a decision maker may determine that the Economic Feasibility criterion is more important than the Technical Risk criterion, and so on. (Ordinal preferences for summary findings are not necessary because the whole number responses are already arranged in a worst-to-best relationship.) However, ordinal preference does not address how much more important one evaluation criterion or summary finding response is than another. The concept of "relative importance" takes this important issue into account by indicating the difference between the evaluation criteria and the summary finding responses in ranked order (i.e., criteria " $\mathrm{X}$ " is 2.5 times more important than criteria "Y").

Assigning relative importance involves answering a structured set of comparative questions about the attributes of each proposal. The personal computer software program Expert Choice was used to help assign the relative importance to the evaluation criteria and summary findings for the test case (Decision Support Software, Inc., 1989). Expert Choice applies the analytic hierarchy process (AHP), a proven methodology for assessing the relative merit of competing options. In the test case, all evaluation criteria and possible responses to all 50 summary findings are weighted by the authors for illustrative purposes.

To assign relative importance to the evaluation criteria, the Expert Choice program asks a decision maker to make pairwise comparisons about the sibling evaluation criteria. (Sibling evaluation criteria emanate from a higher-level criterion.) For example, for the top-level evaluation criteria, the decision maker is asked "Is Economic Feasibility extremely, very strongly, strongly, moderately, or equally more (as) important than (as) Effect on Environmental, Safety, and Health Issues?" (The evaluation criteria listed in this question can be reversed if warranted.) A decision maker selects the answer that most closely corresponds to policy directives and subjective professional judgment. If more than one person is involved in assigning relative importance, either a consensus must be reached for each question or the different answers from participating individuals must be mathematically combined into a 
single answer. All sets of sibling evaluation criteria are submitted to this subjective weighting process.

The number of pairvise comparisons that must be made to completely assign relative importance among fainily members is defined as $[N \bullet(N-1)] / 2$, where $N$ is the number of sibling criteria. In the case of the five top-level evaluation criteria, ten questions were answered (i.e., $[5 \bullet(5-1)] / 2$ $=10$ ). In the test case, 27 sets of sibling evaluation criteria were assigned relative importance using Expert Choice. Again, all questions in the test case were answered solely on the basis of the subjective judgments of the authors for illustrative purposes only.

Relative importance of summary finding responses was assigned similariy. Each summary finding consists of five possible outcomes corresponding to responses on a whole nurnber scale from "1" (worst) to "5" (best). Expert Choice was used to establish, for each set of five summary finding responses, the relative importance of each possible outcome (that is, judgments were made about how much more important a response of " 4 " was, for example, than a response of a "2" for a specific summary finding).

Each set of summary finding responses was treated individually because the range of relative importance for different summary findings varied significantly. For example, the difference between a response of " 4 " and a response of " 3 " for one summary finding may have been small. Consequently, the relative importance that was analytically assigned to the "4" would only be slightly greater than the relative imiportance assigned to the "3." However, for another summary finding, the difference between responses of " 3 " and " 4 " could be more significant, which would translate to a wider range of relative importance.

AHP is well suited for translating the opinions of a decision maker about a diverse set of topics into scyarate, numerical ratings that can be compared and combined into a score for each proposal. Th: Expert Choice program translates the pairwise comparisons that are made aiscut each set of sibling evaluation criteria into numerical weighing factors. Likewise, the program calculates fractional scores for the summary finding responses. These weighing factors and fractional scores are the basis for assigning priority to competing proposals. (No attempt is made here to explain the mathematical operations that are performed by the Expert Choice program. A detailed explanation of these operations is provided in the Expert Choice user's manual (Decision Support Software, Inc., 1989). It should be noted that the AHP methodology used in the test case and, in particular, the Experi Choice program, is only one of several ways to assign relative importance to the evaluation criteria and to the summary finding responses.)

\subsection{Data Collection}

To thoroughly characterize the costs, risks, and benefits of the proposed waste minimization activities, quantitative and qualitative data should be collected. The data must address all important aspects of the waste minimization proposals and must be collected at an appropriate level of detail. The data collection process must also be auditable and demonstrate a clear path to the decisions that are subsequently made. Finally, data collection must be performed in a timely manner so that the usefulness of the entire 


\section{QUANTI1ATIVE}

1. Cost to Implement Proposal

2. Time to Implement Proposal

3. Volume of Hazardous Waste

4. Number of Workers Exposed

5. Toxicity (lethal dose)

6. Activity (mrem/hr)

\section{QUALITATIVE}

1. Effect on Weapon Reliability

2. Effect on Weapon Safety

3. Effect on Community Relations

4. Likelihood of Successful 'mplementation

5. Applicability to General Industry

6. Operational Disruption if Proposal Fails evaluation and prioritization process can be preserved. Table 2-1 presents some of the quantitative and qualitative data that were collected or estimated in order to characterize the waste minitnization proposals studied in the test case.

Quantitative data include measurements of cost, time, waste volume, population exposed, production iates, toxicity levels, and other information that can be expressed numerically. Depending on the scope of the analysis, other or additional quantitative data may be required. Quan'itative baseline datc, desuribing the performance of the systems hefore implementation of the proposed waste minimization activities, should be included if available. These baseline data, when compared to estimates of system performance after the proposed activities are inplemented, will allow evaluators to estimate the net change in costs, risks, and benefits resulting from the implementation of each proposal. Very little baseline quantitative data were available for the test case.

Qualitative data are also important in the characterization of proposed waste minimication activities. Information that carnot be quantified (or that is extremely difficult to quantify), such as effects on weapon reliability and safety, public relations, likelihood of success, or consequences of failure, helps to address many of the intangible costs, risks, and benefits.

In the test case, data were collected at the DOE production facilities through a series of interviews with plant personnel responsibie for the proposed waste minimization activities. Personnel from manufacturing, waste management, data management, and administration were interviewed to obtain a variety of information about the proposed activities. Laboratory personnel who have design respons:bili ' for the facility components 
that will be affected by the proposed activities were also interviewed. General questions covering broad topical areas, such as "What effect will the proposed waste minimization activity have on hazardous waste generation?" and "What is the likelihood that the proposed activity can be successfully implemented?" were explored. The answers to these questions were recorded in logbooks. Later in the analysis, telephone conversations with plant personnel were used to supplement the data collection process if clarification or additional information was required.

We believe, however, that the data collection process can be accomplished in a more efficient and effective manner through the use of standardized worksheets to support the process. Figure 2-4 provides an example of a worksheet that could be used in future applications to focus the data collection process. This woiksheet would document some of the basic infor nation ahout the hazardous materials used in the manufacturing process. Other worksheets (possibly 10 to 20) are needed to thoroughly characterize the quantitative and qualitative data of the proposed waste minimization activities. Documentation material previously developed by the U.S. Environmental Protection Agency (EPA) can be used for or adapted to this evaluation and prioritization process (EPA, 1988 and 1989).

\subsection{Prisritization Technique}

Proposed activities are rated numerically by aggregating the fractional scores associated with each summary finding response and the weighing factors that were assigned to the evaluation criteria.
Each summary finding fractional score is multiplied by the assigned weighing factor for the higher-level evaluation criteria in its direct lineage. The sum of these multiplications for the 50 pathways, from each summary finding to the top of the hierarchy, represents the final score of a proposal. Figure 2-5 illustrates the numeric values that are multiplied and added to calculate a proposal's final score. All mathematical operations for the test case were performed automatically by the Expert Choice software program.

This approach results in a score (or figure of merit) for each proposed waste minimizalion project. The score represents the cumulative benefit that a proposal will bring to DOE. Priority can be assigned by listing proposals in order from highest to lowest scores. Proposals with the same score can be arranged in arbitrary groups. (There is a remote possibility that a proposal may have a negative final score. This means that implementing the proposal will impede the achievement of waste minimization goals.) Proposal scores can also be represented graphically, using different colors and shapes to aid in quick, visual comparisons of the competing projects.

In addition to a single number representing the final score of each proposal, the results of the proposal evaluation can be presented as a set of constituent scores for the five top-level evaluation criteria. That is, the scores attributable to Economic Feasibility; Effect on Environmental, Safety, and Health Issues; Effect on Operational Issues; Technical Risk; and Effect on Intangibles can be displayed for each proposal. Graphic presentation of these constituent 


\section{WORKSHEET \#1A}

\section{MATERIAL CHARACTERIZATION}

\begin{tabular}{|c|c|c|}
\hline 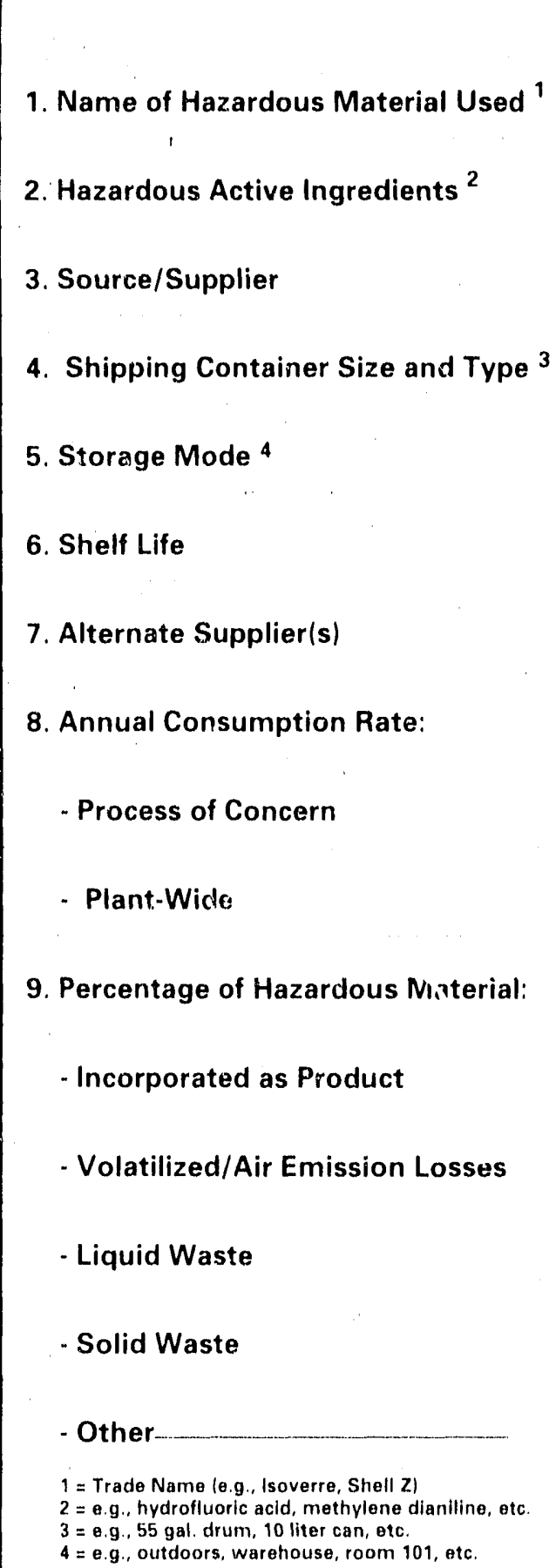 & Current Operations & Proposed Operations \\
\hline
\end{tabular}

Figure 2-4. Example Worksheet for Data Collection 


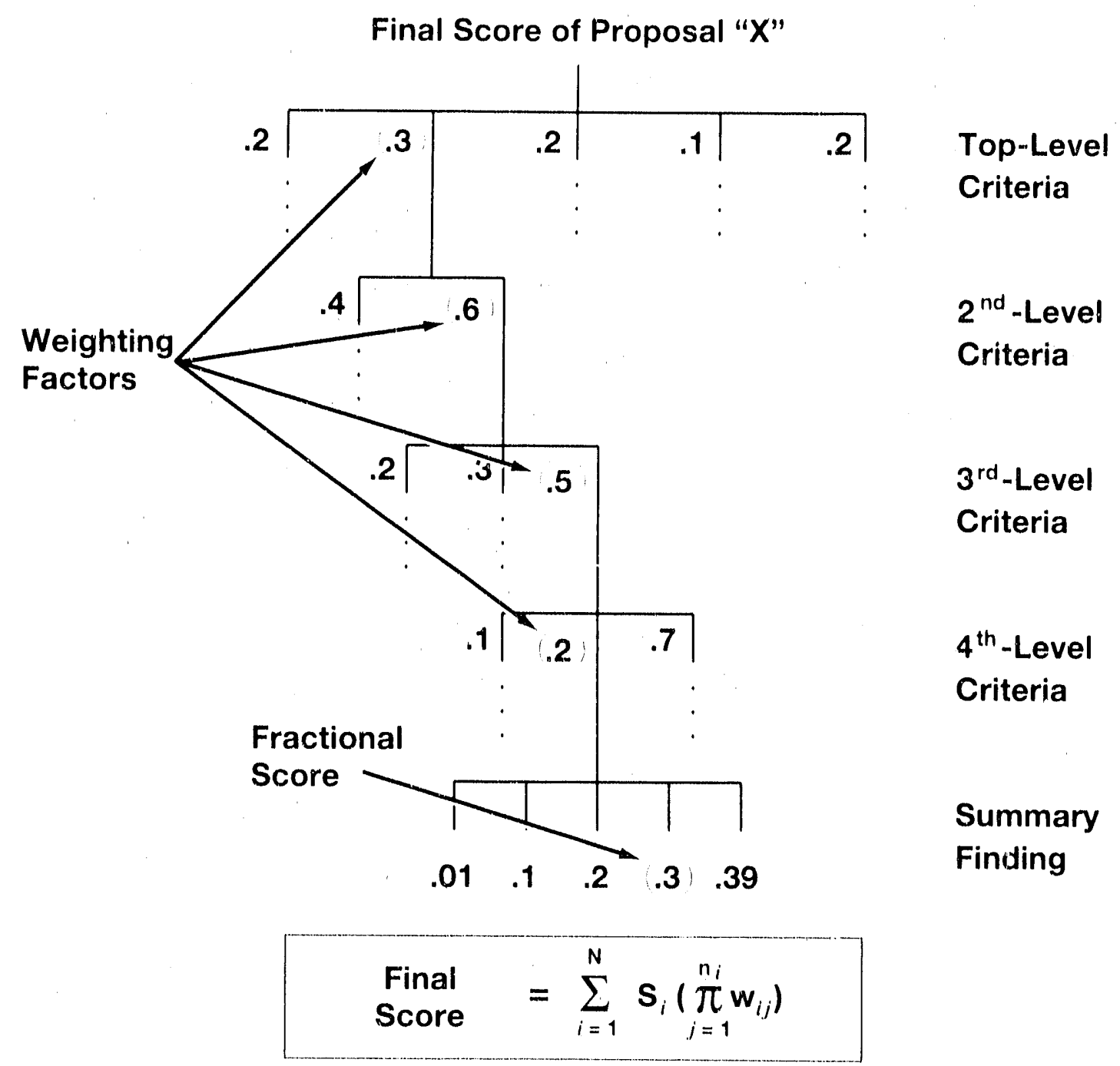

where: $\quad N=$ the number of paths from the bottom to the top of the hierarchy.

$S_{i}=$ the fractional score assigned to the $i^{\text {th }}$ summary finding.

$\mathbf{n}_{i}=$ the number of criteria levels in the $i^{\text {th }}$ path to the top of the hierarchy.

$w_{i j}=$ the weighting factor on the $j^{\text {th }}$ criteria level in the $i^{\text {th }}$ summary finding path.

Figure 2-5. Final Score Computation 
scores can also enhance visual comparison among competing proposals. Using this alternate approach, the decision maker can see the contribution of each major criterion to the final score of a proposal. An example of a graphical presentation is presented in Section 5.0.

\subsection{Optimal Allocation of Funds}

Once a prioritized list of proposed waste minimization activities has been created, the final step is to allocate the available budget to the best set of projects. The simplest approach would be to fund the project with the highest score and continue to fund projects with decreasing scores until the budget is exhausted. The advantage of this approach is that it is easily administered and intuitively appealing. However, the disadvantage of this simple funding method is that it assumes that a project's score is perfectly consistent with its funding priority. Although this assumption may appear justified, it will almost certainly produce suboptimal results. For example, the proposed project with the highest score of merit may cost more to implement than the entire budget. Another problem with this simple approach is that it does not consider the additive properties of the proposal scores. For instance, if the five projects with the highest scores are selected for funding so that the available budget is exhausted, it is quite possible that another set of projects would produce a higher total score (and thereby provide a greater total benefit) and still remain within the DOE budget. If the ultimate goal of the evaluation and prioritization process is to select, from a large and diverse set of waste minimization proposals, the set that maximizes DOE benefit within a limited budget, all possible combinations of proposals must be considered before an optimal set is identified. (A corollary to this argument is that there is no inherent reason why the project with the highest score should always be selected for funding.)

Optimal allocation of funds requires a slightly more sophisticated technique. The method presented here is a version of a linear programıming approach called "zeroone linear integer programming." Linear programming techniques are wcll understood and have been developed previously for DOE to allocate funding among competing projects (Hockert and Hulme, 1989). These techniques are easy to use and can accomplish exhaustive computations rapidly. Simply put, the optimal allocation of a limited budget among competing projects is analoggous to packing a box with a number of objects of disparate volumes and values. If the goal is to fill the box with objects of the highest total value while not exceeding the box volume, the goal will more likely be satisfied by carefully selecting the objects to be included rather than by packing the box with the most valuable object first, then the second most valuable, and so on, until no other objects fit. The simple method may arrive at a reasonable solution to this type of problem, but the linear programming approach will always produce an answer at least as good as the simple method.

To implement the linear programming approach for proposed waste minimization projects, four types of information are needed:

1. A score (or benefit measure) for each proposed project,

2. The overall budget for waste minimization activities, 
3. The annual cost of each proposed project, and

4. An explicit description of the funding constraints that will be imposed on the process.

Estimation of a score for each proposal (Item 1) is discussed in Section 2.5. Items 2 through 4 are readily available from the data collected about each proposal and the budgetary guidelines that are provided to or developed by the DOE decision maker.

A single, comparable score for each proposed activity is necessary if the linear programming approach is to be used. Whether it is computed using decision support software or arrived at through the subjective judgment of the decision maker, the score of each project must ultimately be expressed in the same units (or as a unitless value). In terms of the box packing example described earlier, the score of each proposed waste minimization activity is analogous to the value of each object that could be placed in the box. The score represents the level of improvement that will accrue to DOE from the implementation of each proposal.

The overall budget for waste minimization activities is another essential element in the linear programming approach to this problem. The budget should consist of all possible funding sources that will be used to support waste minimization projects. A total budget figure provides the fundamental constraint that cannot be violated and, with respect to the box packing problem, is similar to the volume of the box.

Another type of information required for the linear programming approach is the annual cost to implement each proposal. Annual cost figures are necessary to allow a consistent means of comparing projects with widely dissimilar funding requirements. Describing projects by their annual costs also provides a way to measure the rate at which the anticipated benefits are introduced into the DOE system. Assuming that the incremental benefit provided by a proposal is proportional to the incremental cost of the project, it is possible to subdivide the total benefit into annual portions that correspond to the annual cost. Thus, tivo proposed projects that have the same score and total cost to implement may not be assigned equal funding priority because of the liming of the costs and benefits. The annual cost of each proposal is like the volume of the objects to be packed in a box. Each project will occupy a portion of the DOE annual budget, much like each object will occupy a given volume in the box.

Finally, it is necessary to know any additional funding constraints (other than the total budget limit) that must be observed. Additional constraints are explicit rules that must be met when the funding is allocated. For example, one constraint might be that the total funds allocated to basic research projects must constitute between 5 and 6 percent of the total budget. Another constraint might be that every DOE facility must receive at least $\$ 1$ million in funds. Of course, all constraints must be acceptable to the decision maker. Any number of funding constraints are acceptable, but each must be expressed in mathematical terms. In the box packing analogy, an additional funding constraint is like a weight limit imposed on the total contents in the box. If each object also has a different weight, the packing process is further complicated 
because volume, value, and now weight objectives must be met.

\subsection{KEY PARTICIPANTS}

This section presents a strategy for organizing a formal evaluation and prioritization process for DOE waste minimization proposals. Under this strategy, four main groups would participate in the future development, application, and refinement of the evaluation process. A brief description of the roles of each of these key participants is provided below.

Proposers: DOE facilities that prepare waste minimization proposals (ADSs, field work proposals, etc.) or private companies that seek DOE waste minimization funding.

Working Groups: DOE-appointed groups consisting of technical, financial, and policy personnel familiar with waste minimization issues. These groups are formed to support and refine the evaluation and prioritization process.

Evaluation Groups: Standing or annuallyconvened groups of DOE personnel responsible for evaluating waste minimization proposals and providing recommendations to a decision maker.

Decision Maker: The DOE individual (presumably the OTD Associate Director) with the ultimate responsibility for selecting and funding waste minimization proposals.

Figure 3-1 presents an overview of the evaluation and prioritization methodology and how the participants in the overall process interact.

\subsection{Evaluation Criteria Development}

The evaluation criteria in Appendix A were developed specifically for waste minimization process changes within the DOE nuclear weapons complex. If the set of criteria must be modified for another application, we recommend that a DOEappointed working group coordinate these activities. Modified evaluation criteria should be developed from the composite input of all DOE offices and operating facilities seeking OTD waste minimization funding. By involving these organizations in the selection of the most relevant criteria, a clear and consistent expression of DOE's expectations will be available to proposers, evaluators, and the decision maker.

\subsection{Proposal Scoring Method}

If summary findings are used by DOE to support its existing proposal selection process, we recommend that evaluation groups currently reviewing waste minimization proposals refine the summary findings presented in Appendix B. Separate DOE-appointed working groups, consisting of technical experts familiar with waste minimization processes, should assist this effort. One of the first responsibilities of these groups would be to develop a numerical range for each summary finding response that reflects the consensus of DOE management, design laboratories, and production facilities.

We also recommend that guidance be provided to the individuals completing the summary findings, including clear instructions for handling quantitative data and for interpreting qualitative data. 


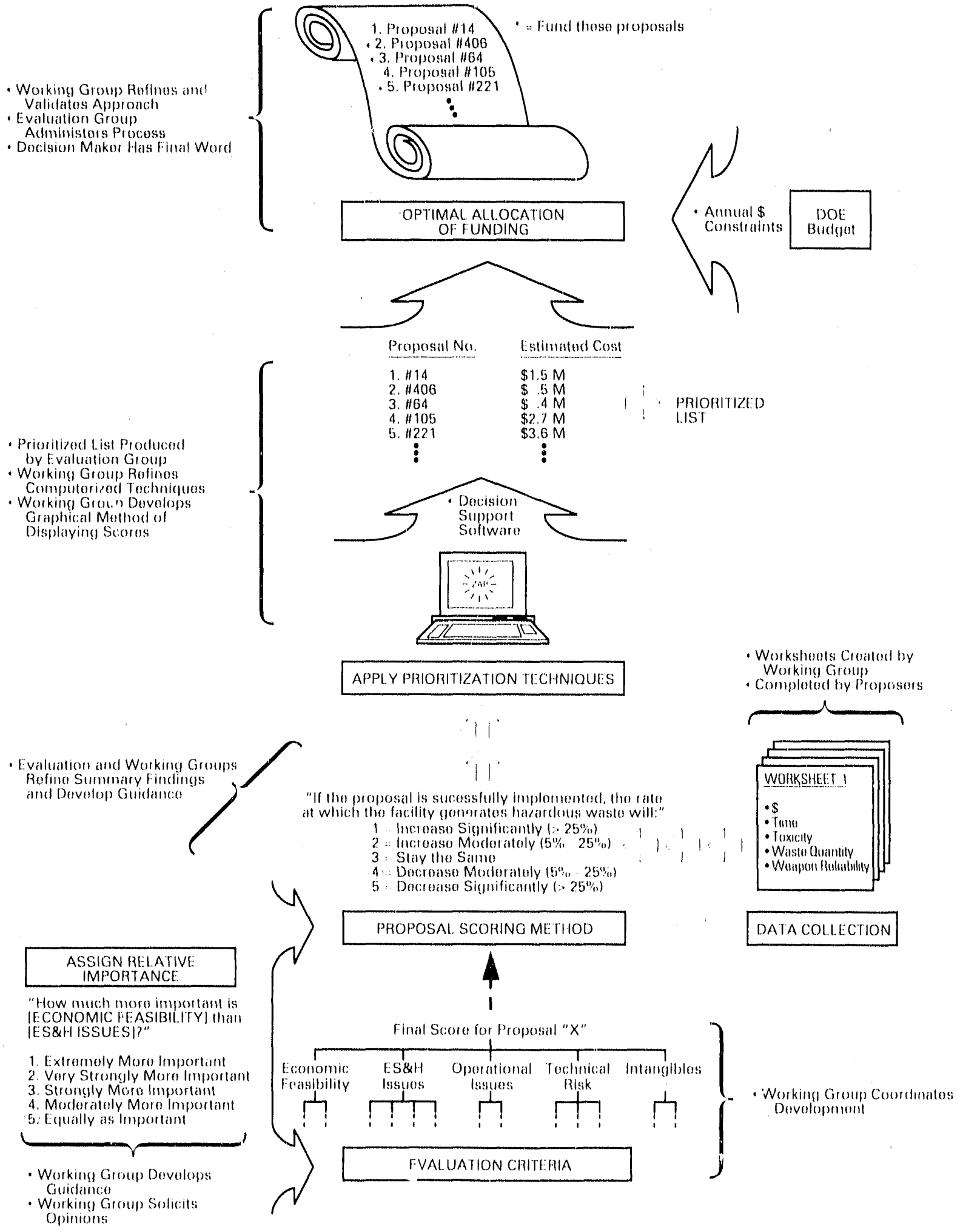

Figure 3-1. Evaluation and Prioritization Process and Key Participants 
Hypothetical examples should also be provided to assist analysts in selecting summary finding responses. Evaluation groups and working groups should work develop this guidance.

Finally, we recommend that summary findings forms be completed by evaluation groups. Using the proposal data and guidance, the evaluation groups would mark the appropriate responses for each proposal. They would also contact the proposers to clarify ambiguous data or obtain missing information.

\subsection{Assigning Relative Importance}

In a formal evaluation and prioritization process, the assignment of relative importance to evaluation criteria and summary findings should be coordinated by a single group. We recommend that a DOL-appointed working group be formed with the specific responsibility of soliciting the opinions of key participants in the process (the decision maker, evaluation groups, and proposers). The working group should also develop guidance to solicit, document, and combire the various opinions that are received. In particular, efforts should be made to request opinions from participants in the process that closely correspond to each individual's professional perspective. For example, the relative importance of the highest-level evaluation criteria are best answered by the decision maker. Lower-level criteria and summary findirgs could be assigned relative importance by the composite opinion of the evaluation groups and proposers.

Finally, the working group should combine the various opinions into a preliminary set of weights for the evaluation criteria and summary findings. These preliminary results should be re cwed by all participants so that a final consensual set of weights can be produced.

\subsection{Data Collection}

Supplemental worksheets could be created by a working group whose members have broad experience in the area of waste minimization. Ideally, members of the working group that developed the evaluation criteria would assist in the development of these worksheets. These two tasks should be addressed collectively because proposal data are eventually judged against the evaluation criteris. The working group should also provide guidance for completing the worksheets. Clear examples of the types of information sought (and the assumptions that should be made) can be included in this guidance.

Worksheets should be completed by the proposers of waste minimization activities. The members of the working group that created the worksheets should be available to answer questions from proposers. Once the worksheets (and other proposal documents) have been completed for a proposal, an entire submission should be transmitted to the appropriate DOE field office for preliminary verification and review. The field office would then transmit the proposals to the OTD evaluation groups.

\subsection{Prioritization Technique}

The DOE evaluation group should produce a prioritized list of waste minimization proposals. The group can rely on computer software to aggregate proposal scores and to provide an initial proposal ranking to the decision maker. A working group should either refine the computerized prioritization techniques 
used in the test case or develop another procedure that is acceptable to the evaluation group. The working group can also devise methods to graphically display proposal scores in a manner that visually and quickly informs the decision maker.

\subsection{Optimal Allocation of Funds}

Although a conceptual description of the optimal allocation of funds is presented in Section 2.6, this step was not performed in the test case because the small number of proposals that were studied could not provide an adequate demonstration of the linear programming approach. Nevertheless, this technique can be applied in larger applications of the evaluation and prioritization process. We recommend that a working group be appointed to refine and validate the approach outlined in this report. Eventually, the DOE evaluation group could administer this step and provide recommendations to the decision maker about the optimal allocation of DOE funds among proposed waste minimization activities. We also recommend that the working group develop procedures to inform all proposers of the results of the evaluation and prioritization process and to receive comments from all participants so that the process can be continually improved.

\subsection{PROPOSED WASTE MINIMIZATION PROJECTS}

This section describes the proposed waste minimization projects that were evaluated and prioritized in the test case analysis. Two research and development programs currently supporting changes to nuclear weapons manufacturing processes were investigated -- (1) the elimination of an acid rinsing process at the Rocky Flats Plant, Golde:., Colorado and (2) the development and demonstration of a less hazardous potting material at the Pinellas Plant, Largo, Florida.

\subsection{Rocky Flats Test Case Study -- Reservoir Rinsing}

The first proposed process change evaluated in the test case involves the elimination of an acid immersion process currently used to rinse stainless steel reservoirs at the Rocky Flats Plant. This process change, if successful, will reduce the volume of hazardous acid waste generated at the plant by 5 percent.

\subsubsection{Description of Waste Minimization Process Change}

One of the major manufacturing activities at the Rocky Flats Plant is the production of stainless steel reservoirs and their connecting hardware. Reservoirs are produced in Building 460 by a series of turning, drilling, and grinding steps using standard machine tools. No nuclear material is used in these processes.

Currently, reservoir components are rinsed using an automated immersion system consisting of several tanks containing nitric acid, hydrofluoric acid, aqueous detergent, and deionized water. The historical reasons for this multi-step rinsing process are to enhance the non-permeability characteristics of the stainless steel and to prepare the attached stem tubing for future welding operations.

Approximately 2000 gallons of concentrated acid (nitric and hydrofluoric) are discarded from this process annually. Furthermore, the deionized water in some 
rinse tanks quickly becomes contaminated with residual acid carried from bath to bath by the stainless steel components. The contents of these tanks must be continually replenished with fresh deionized water. This requirement leads to the creation of about 800,000 gallons of hazardous acid waste each year, approximately 5 percent of the 15 million gallons of hazardous acid waste produced annually at the Rocky Flats Plant. All hazardous acid waste generated at the plant is transferred to a central processing facility, treated, and packaged for disposal.

Most of the hazardous acid waste generated at the Rocky Flats Plant is from plutonium recovery activities. Because the acid used in plutonium recovery activities becomes contaminated with radioactive material, the resultant waste stream is categorized as mixed waste. Furthermore, the central processing facility combines the hazardous acid waste streams from all areas of the plant. This practice eventually causes all hazardous acid waste streams (including the 800,000 gallons of acid waste from the non-radioactive reservoir-rinsing procedure) to become mixed waste. Currently, neither regulatory guidelines to dispose of mixed waste nor a burial facility to accept mixed waste exists. Therefore, all mixed waste at the Rocky Flats Plant must be stored on-site until the situation is resolved and a disposal facility is available.

The waste minimization proposal at the Rocky Flats Plant is designed to determine whether or not the nitric and hydrofluoric acids used in the rinsing process can be eliminated. The goal of this program is to demonstrate that rinsing with aqueous detergent and deionized water alone is acceptable. In 1986, Los Alamos National
Laboratory (LANL), the design laboratory responsible for approximately half of the reservoirs built at Rocky Flats, began conducting chemical and metallurgical analyses of block stainless steel rinsed only with a mild aqueous detergent. The results of these preliminary analyses were promising and, in 1989, welding and permeability studies were initiated at Rocky Flats using sample LANL reservoirs. Welding studies were also initiated in 1989 using reservoirs designed by SNL, Livermore. The final results of these studies are expected in 1991, at which time a formal change in the existing acid rinse procedure could be considered.

\subsubsection{Anticipated Benefits, Risks, and Costs}

If this waste minimization project is successful and acid is eliminated from the reservoir-rinsing procedure, the Rocky Flats Plant will reduce the annual amount of hazardous acid waste currently generated at the plant by 5 percent. (Note that the Rocky Flats Plant generates many other types of hazardous wastes. Although hazardous acid waste generation will be reduced by 5 percent, the total hazardous waste generated at the plant will be reduced only marginally.)

Some benefits from the reduction of hazardous acid waste are intangible. For example, because the number of plant workers exposed to acid will be reduced, the risk of safety and health accidents occurring at Rocky Flats will decrease. Furthermore, the risk of environmental contamination (because of handling, treatment, storage, or disposal accidents) will decrease because the quantity of waste generated that is classified as mixed waste will be reduced. 
The tangible benefits that are anticipated from this process change are the savings in process-related and waste management costs. Process-related savings in manpower was estimated at about $\$ 57,000$ per year. Larger savings, however, will most likely be associated with the handling, treatment, storage, and disposal of the $8(0), 000$ gallons of hazardous acid waste (which becomes mixed waste) generated in the process each year. These costs could not be determined for the test case but are discussed below in a qualitative manner.

Waste handling savings include the reduced cost of both direct labor and the containers used to transport hazardous acid waste to the central processing facility. The Rocky Flats Plant has been advised recently that all containers used for on-site transport of concentrated acid must meet special design requirements imposed by the Department of Transportation (Code of Federal Regulation, 199()). ${ }^{3} \quad$ Meeting these requirements will result in rising waste management costs at the plant because the new containers must be disposed of as hazardous solid waste after only one use. Not only does this increase the budget for transportation containers, but the disposal cost of the resultant hazardous solid waste will escalate significantly. The elimination of acid from the reservoir-rinsing process will allow the plant to avoid some future operational expenses.

Treatment and storage costs will also be reduced because the volume of hazardous process waste transported to the central processing facility will be reduced by 5 percent. Treatment costs and potential cost savings are difficult to estimate without a detailed analysis of the central processing facility and are not discussed further. The cost of storing mixed waste at the Rocky Flats Plant is even more difficult to measure. Recently, the plant has erected two large tents to store thousands of drums of mixed waste inside the plant security perimeter. The associated security, maintenance, and accountability costs for storage of mixed waste in a temporary structure may contribute significantly to the fixed costs at the plant. Eliminating $80,0,000$ gallons of hazardous acid waste directly translates to a mixed waste storage cost savings.

Finally, the disposal cost of mixed waste is almost impossible to estimate at this time. Once the regulatory and political issues are resolved and a mixed waste disposal facility is built or approved, the cost of transporting and disposing of drums may be quite large. Despite the uncertainty of future disposal costs, reducing the rate at which mixed waste is generated can only reduce the future total cost.

The primary risk (or, more precisely, the most damaging potential consequence) associated with changing the existing acid rinsing procedure is that reservoirs may experience rinsing-induced welding failures or develop permeation problems while in the weapons stockpile. Reservoirs are used in all current weapons systems and all reservoirs are rinsed using the same process. Therefore, any change to the rinsing process introduces a potential

3 Code of Federal Regulation (CFR), January 1990. Etching Acid Liquid, n.o.s., 49 CFR 173.299. 
common-mode failure that could have widespread consequences. The potential consequences of reservoir failure in the stockpile are very large. The costs for decontaminating affected areas, replacing suspect reservoirs, and requalifying the production processes are examples of the consequences that could occur. Similarly, the national defense consequences are immeasurable if the reliability and availability of the stockpile are diminished. The time required to replace, the reservoirs, including requalification of the production processes, could negatively affect the entire weapons production schedule. Although production and design personnel believe that the likelihood of welding failures or permeability problems caused by this process change is extremely low, the potential consequences suggest that the risks involved in this waste minimization initiative are significant.

The total cost of verifying the acceptability of aqueous detergent reservoir-rinsing is currently estimated at $\$ 1.7$ million (undiscounted), and consists of three major research and manufacturing expenses. First, approximately $\$ 120,000$ was spent from FY86 to FY89 on preliminary chemical and metallurgical analyses. Second, detailed welding and permeability studies are scheduled for FY90 and FY91 at a total cost of about $\$ 90(0,000$. Finally, LANL has required a shelf life storage (SLS) program to monitor the long-term performance of reservoirs rinsed in aqueous detergent. An SLS program is performed, if possible, whenever a change in a weapon design or manufacturing process poses a significant risk to the safety, performance, or reliability of weapons in the stockpile. In this case, the SLS program requires placing several finished reservoirs in storage where they are continually monitored and periodically tested and analyzed. The SLS program will start one year before the aqueous rinsing process is formally instituted (in order to provide a one-year advanced warning of impending problems) and will continue as reservoirs are produced and introduced into the stockpile. With an estimated start date of FY92, the reservoir SLS program is scheduled to continue for 18 years at a total cost of $\$ 700,000$ (for L.ANL-designed reservoirs only).

\subsection{Pinellas Test Case Study -. Magnetic Component Putting}

The second proposed waste minimization process change evaluated in the test case involves the development and testing of a less hazardous material to replace a substance suspected to be a human carcinogen currently used in the potting of magnetic components at the Pinelias Plant. The implementation guidance to $\mathrm{DOE}$ Order $54(0) .1$ states that source reduction, the first priority in the DOE waste minimization program, can be achieved by reducing the toxicity of generated waste (DOE, 1988b). Although this process change will not decrease the rate at which hazardous waste is generated at the plant, toxicity reduction mitigates present and future human health and environmental risks.

\subsubsection{Description of Waste Minimization Process Change}

The Pinellas Plant produces electronic and neutronic components used in many nuclear weapons systems. One of the procedures at the plant involves the potting (encapsulation) of four types of components to form subassemblies: magnetics, neutron generators, thermal batteries, and transducers. Potting is a 
manual operation performed by workers under fume hoods and wearing gloves and masks. The potting material, which is a mixture of an epoxy, a filler material, and a curing agent, is mixed by the same workers performing the potting oneration. The curing agent, called Shell $\mathrm{Z}$ hardener, contains methylenedianiline (MDA.), a compound that has recently been recognized by the EPA as a potentially carcinogenic substance. Based on the EPA findings, the Occupational Safety and Health Administration (OSHA) has established extremely low worker-exposure limits for MDA. Although the potting operation using Shell $\mathrm{Z}$ hardener could continue if stricter handling procedures were followed (e.g., additional protective clothing, respirators, mandatory showers, etc.), the management of the Pinellas Plant is committed to replacing Shell $\mathrm{Z}$ hardener with a less hazardous material.

Starting in 1984, Pinellas and SNL, the design laboratory responsible for the potted components, initiated process development studies to identify less hazardous alternatives to Shell $\mathrm{Z}$ hardener. By 1986, chemical and mechanical compatibility tests indicated that a curing agent called Ethacure 100 could reasonably replicate the desired properties of Shell $\mathrm{Z}$ hardener. The active ingredient of Ethacure 100 , diethyltoluenediamine (DETDA), is less toxic than MDA. Functicnal testing began in 1986 on selected components and will continue for the remainder of the components involved in potting operations until August 1990. Although the ingredients of the proposed potting material have not changed since 1986, the proportions of the epoxy, fillers, and Ethacure 100 have been adjusted several times to account for individual product and process peculiarities. The new potting material will be introduced to the production lines by the end of 1990 . (The test case analysis was limiled to the evaluation of the potting of magnetic components. The benefits, risks, and costs associated with other affected components, such as neutron generators, thermal batteries, and transducers, were not assessed in an attempt to simplify the characterization of this waste minimization process change.)

\subsubsection{Anticipated Benefits, Risks, and Costs}

If a new potting material using Ethacure 100 can be developed for magnetic components, a suspected carcinogen will be eliminated from the workplace and the risks to human health and the environment will be reduced. The toxicity of DETDA, the active ingredient in Ethacure 100, is considered low to moderate if ingested internally. Incidental contact with the skin produces no noted health effects. Furthermore, preliminary test results indicate that DETDA is noncarcinogenic, a marked improvement over the MDA used in Shell $Z$ hardener. An ancillary benefit attributable to the reduced health risk to employees is the improvement in worker relations. In addition, workers have expressed concerns that m-phenyldiamine (MPDA), an offgas produced by MDA that has discolored the walls of the potting area, might post an unrecognized health risk. Elimination of MDA and MPDA from the workplace will likely bolster worker morale and productivity.

is with all potentially significant process changes, the most threatening risk is an unforeseen failure that could occur after the weapons are placed in the stockpile. Potted magnetic components are used in 
many different systems in all nuclear weapons. Changing potting materials introduces possible common-mode failures to all newly-produced weapons. Moreover, magnetic components are frequently used in applications where failures can' only be detected by stockpile sampling and testing programs. If a new potting material causes the failure of magnetic components while in the stockpile, not only must a new recipe be developed (or the previous recipe reinstated), but all affected weapons will most likely be returned to the production facilities for disassembly, examination, and retrofitting. Although nuclear material contamination will not occur if magnetic components fail, the financial, military, and political consequences of such a possibility are very large.

Production and design personnel at Pinellas and SNL have expressed ligh levels of confidence that a suitable replacement for Shell $\mathrm{Z}$ hardener can be identified. Also, these individuals have stated that the likelihood of a pottingmaterial-induced magnetic component failure in the stockpilc is extremely low if the results of the functional tests currently in progress are positive. Nevertheless, the likelihood and potential consequences of a potting material failure suggest that the risk of ai:is process change is comparable to that of the reservoir-rinsing process change described in Section 4.1.2. The risk of significant production disruption may be greater in the Pine!!as case because a comprehensive SLS program will not be conducted. The costs to monitor and test magnetic components in an effective SLS program have been deemed prohibitively expensive.

The total cost of identifying, testing, and validating a new potting material for magnetic components is difficult to measure because the initial chemical characterization studies (applicable to all components) were conducted using neutron generator process development funding. However, a conservative estimate places the final cost of the Shell $\mathrm{Z}$ hardener replacement program (attributable to magnetic components) at about $\$ 700,000$. Of this cost, approximately $\$ 360,000$ was used for basic chemical research to identify an alternate curing agent and to develop a prototype recipe. The remaining $\$ 340,(00)$ has been used for functional testing and research support for responding to unforeseen problems.

\subsection{TEST CASE RESULTS}

The evaluation and prioritization methodology presented in Section 2.0 was applied to the two proposed waste minimization projects discussed in Section 4.0 to demonstrate the process and to identify possible improvements in the methodology. After the evaluation criteria and summary findings were developed and assigned relative importance, three major activities were performed in the test case:

1. Proposal data were translated into constituent, fractional scores based on the summary finding responses,

2. Summary finding scores and evaluation criteria weighing facturs were combined to obtain individual scores for the top-level criteria of each proposal, and

3. A final score was developed for each proposal. 
An example of the summary findings completed for each proposal is given in Figure 5-1. Summary findings completed for the Rocky Flats and Pinellas proposals are presented in Appendices $C$ and D, respectively. The data used to support each summary finding response are also included in the appendices (represented as "Comments" following each summary finding response). Summary finding responses are based solely on the authors' interpretations of the data and do not neressarily reflect the results that would be obtained in a formal evaluation by a team of DOE analysts. A complete tabulation of the data collected about each proposal is not presented in this report. We present only the information that was used to respond to the summary findings, including the costs and cost savings that were identified for each proposed process change. Figures 5-2 and 5-3 present cash flow diagrams that were used to calculate the net present value (NPV) for each proposal. All costs and cost savings were discounted to the first year of each project. (It was assumed that all the documented costs and cost savings were known before the project began.) It is important to note that many of the anticipated cash flows could not be determined during the test case. In particular, many of the cost savings were impossible to quantify without a more detailed analysis of the operations of each plant. For this reason, the Rocky Flats and Pinellas proposals appear financially unattractive because each has a large, negative NPV.

The Expert Choice software produced a final score for each proposal by combining the summary finding scores with the weighing factors assigned to the evaluation criteria. In addition, individual scores for the top-level criteria were calculated for each proposal. As discussed in Section 2.0, many different decision analysis techniques can be applied to combine the summary finding responses and the evaluation criteria weighing factors to calculate scores for the top-level criteria. The results presented in this section are intended to represent the types of information that can be produced using appropriate decision analysis techniques.

The final scores in the test case demonstration were .35 for the Rocky Flats Plant acid elimination proposal and .24 for the Pinellas Plant potting material replacement proposal. The scores are normalized values on a scale of 0 to 1 , where a "1" represents the best possible score. The weighing factors and the scores calculated for the top-level criteria are given in Table 5-1. The same information is displayed graphically in Table 5-2. (The graphical form of presentation was developed as a result of suggestions made by the working groups at the DOE Cost Model and Risk/Benefit Analysis Workshop.) The numerical and graphical presentation methods illustrate the contribution that each top-level criterion makes to the final score and provide more detailed input to the decision maker.

The principal reason that the Rocky Flats proposal is more attractive than the Pinellas proposal is that it provides greater environmental, safety, and health benefits. The Rocky Flats proposal also scores slightly higher in the areas of Economic Feasibility, Effect on Intangibles, and Technical Risk. As we have stated previously, however, these judgments are based on the authors' interpretations of the proposal data, the authors' opinions regarding the summary finding responses, and the relative importance assigned by 
If the proposal is successfully implemented:

(Evaluation Criterion II.A.1.a)

8. The rate at which the specific

process generates hazardous waste

will:

$1=$ increase significantly $(>25 \%)$

$2=$ increase moderately ( $5 \%$ to $25 \%$ )

$3=$ stay the same

$4=$ decrease moderately ( $5 \%$ to $25 \%)$

$5=$ decrease significantly $(>25 \%)$

Comment: Process change will save 800,00 gallons of hazardous acid waste annually. 15 million gallons of hazardous acid waste generated at Rocky Flats annually. Process change will completely eliminate acid in process.

(Evaluation Criterion II.A.1.b)

9. The rate at which the entire facility generates hazardous waste will:

$1=$ increase significantly $(>25 \%)$

$2=$ increase moderately ( $5 \%$ to $25 \%$ )

$3=$ stay the same

$4=$ decrease moderately ( $5 \%$ to $25 \%$ )

$5=$ decrease significantly $(>25 \%)$

Comment: Proposed savings very small with respect to entire plant hazardous waste.

Figure 5-1. Completed Summary Findings 


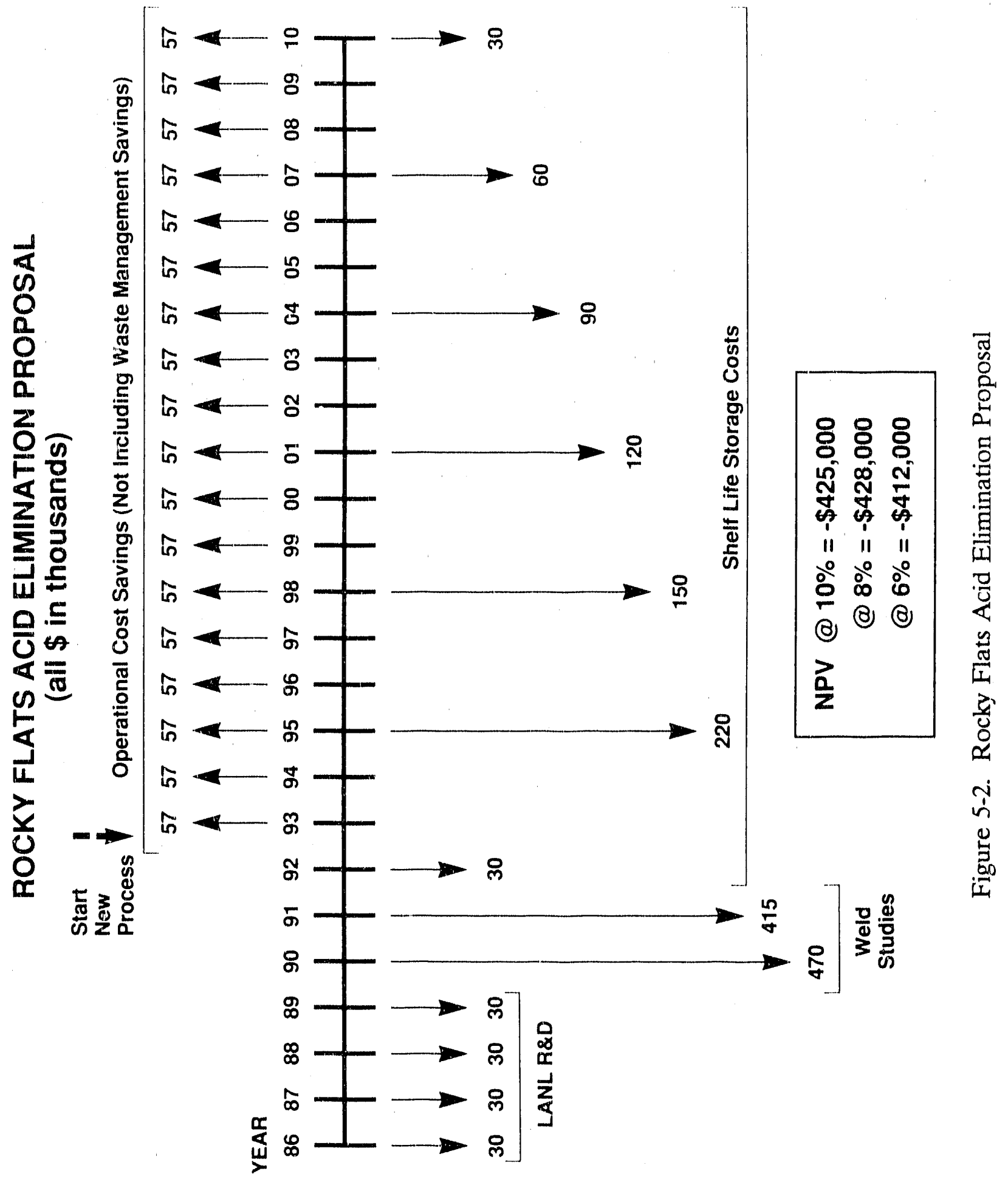




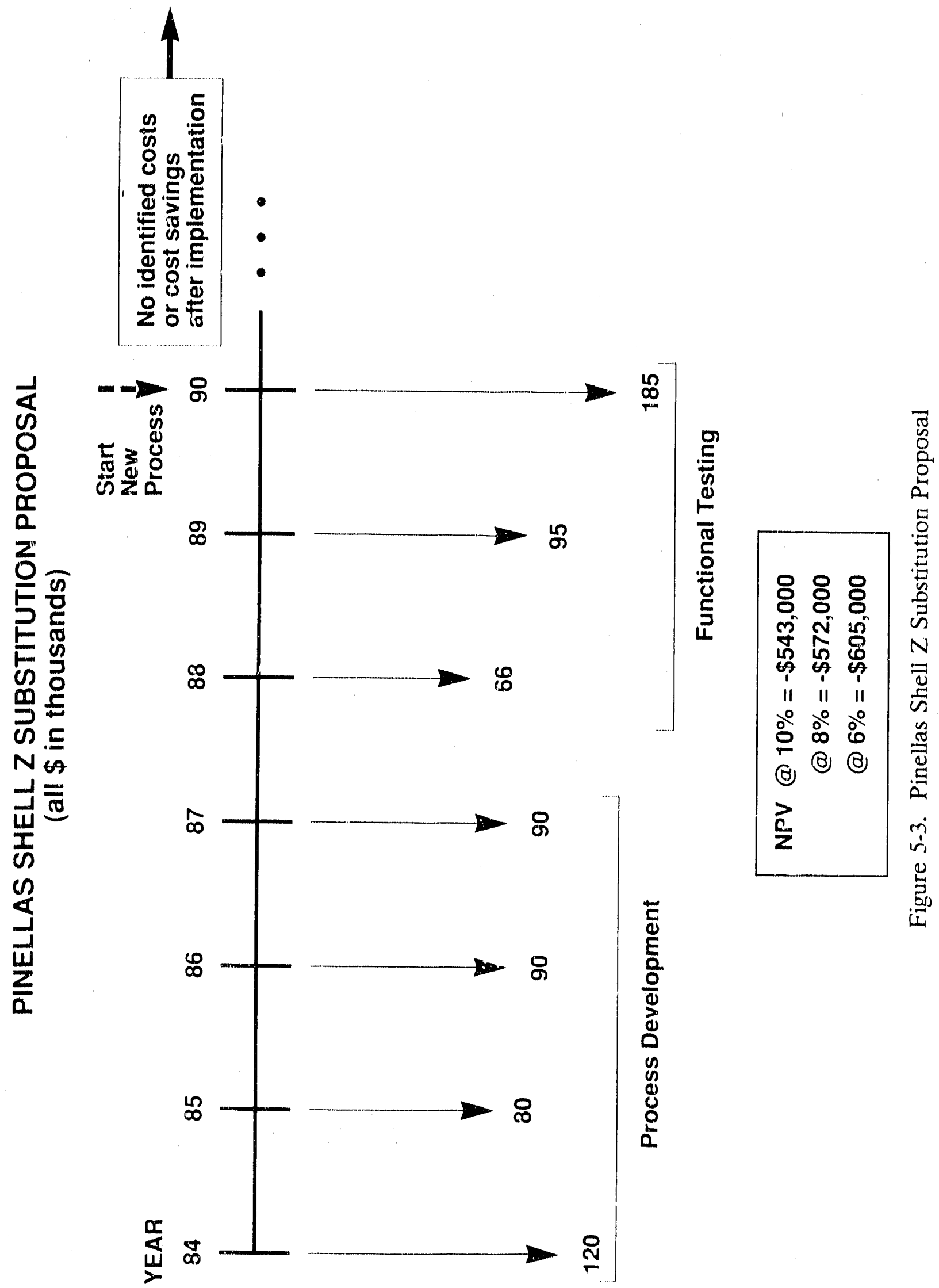




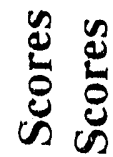

哥营

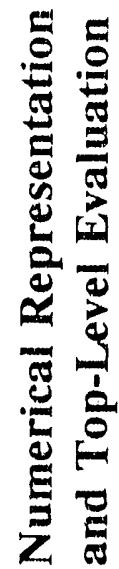

in

$\frac{0}{0}$

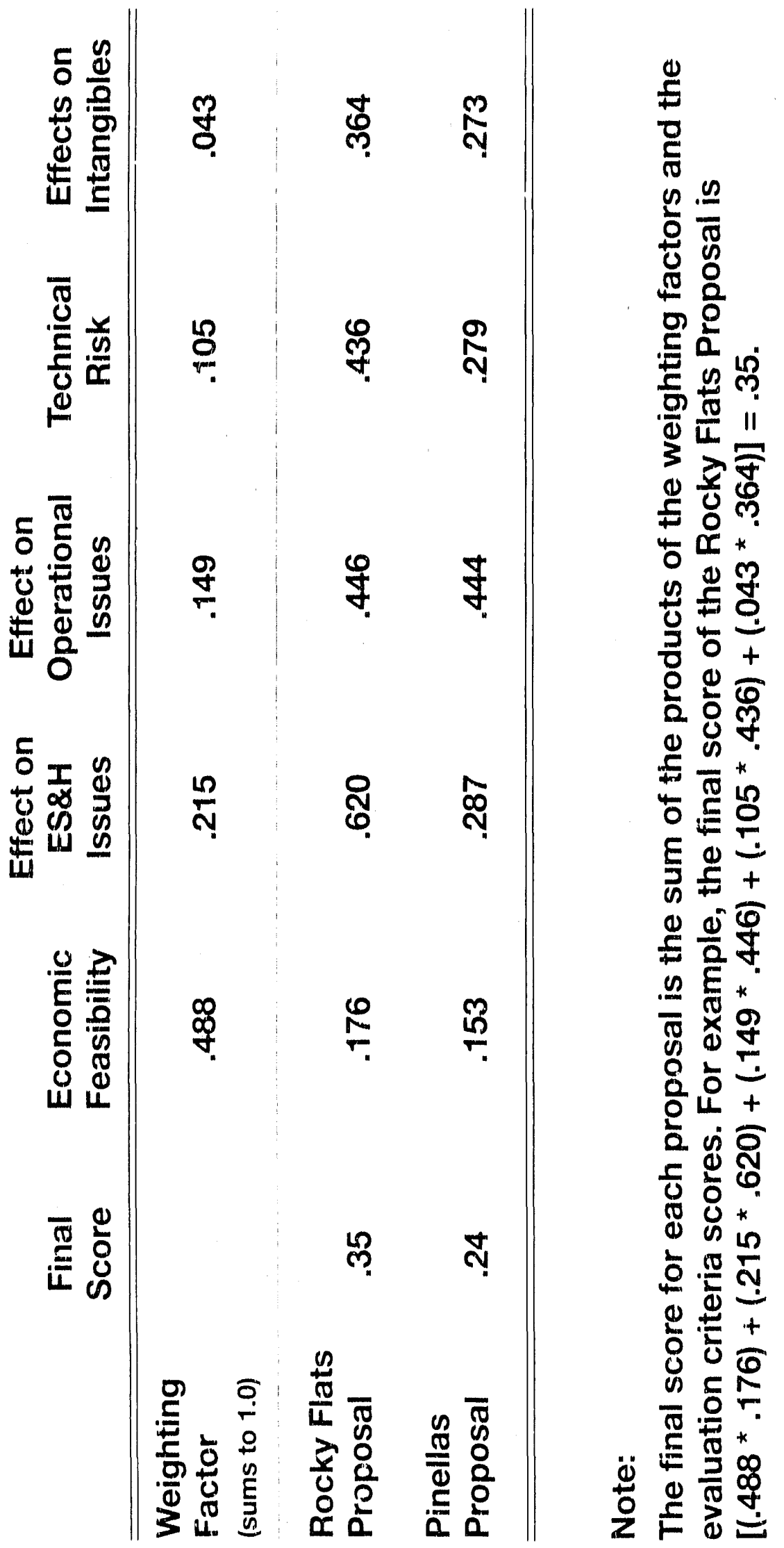




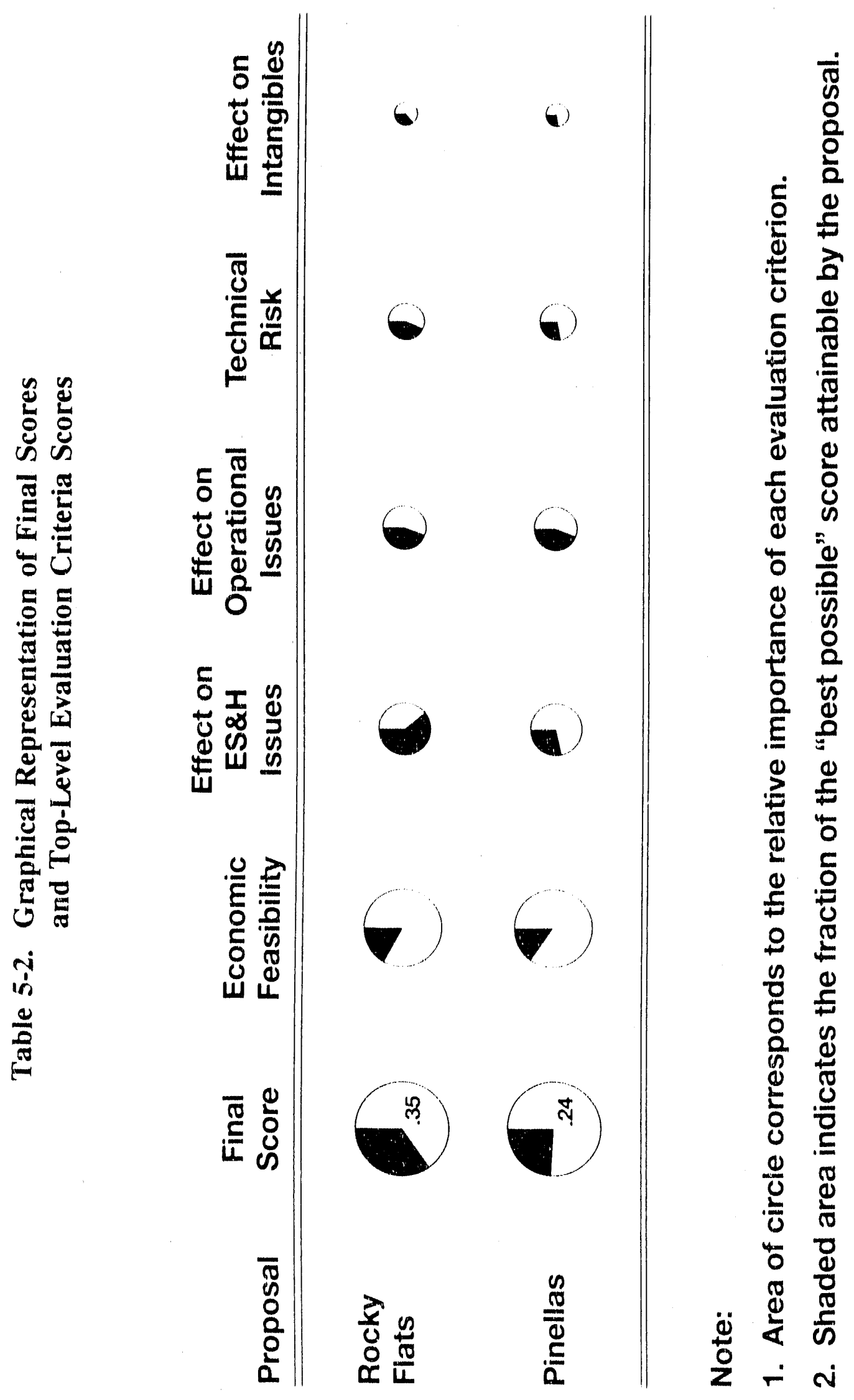


the authors to the evaluation criteria and summary findings. The final scores might change significantly if other evaluators performed the scoring and weighing, or if additional data describing the proposals were available.

Although this evaluation and prioritization method provides insights about one proposal's advantages over another, it does not indicate, in any absolute sense, whether either of the proposals is "good" or "bad." An absolute standard is necessary to distinguish between proposals whose implementation would have positive, negative, or no effects on waste minimization goals. During the test case, no attempt was made to establish a threshold score above which proposals should be considered for funding and below which proposals should be discarded. SNL subsequently addressed this issue and developed a scoring and weighing approach that allows meaningful comparisons of proposal scores to an absolute standard (Hulme, 1990). This approach can be readily adapted to the existing evaluation and prioritization process to screen out proposals that should not receive further consideration.

In order to compare the benefits of the waste minimization activities discussed in this report to the benefits of other proposals, DOE would need to apply this evaluation and prioritization process to all projects under consideration. The results of such an application would provide a ranked list of all projects competing for funding and would assist DOE in selecting a set of projects that maximizes the overall benefits to the ager cy. Application of the optimization process described in Section 2.0 would provide a means for identifying sets of proposals that provide the maximum benefit to DOE at a cost within the available budget. The results of the test case should be considered welldocumented inputs to the decision maker and not the end point of the decision process. The decision support techniques discussed in this report can only supplement, never replace, the decision maker's judgment.

\subsection{CONCLUSIONS AND RECOMMENDA'TIONS}

This report describes a formal process for selecting, from a diverse set of proposed waste minimization activities, those activities that provide the greatest benefit to DOE. A methodology for evaluating and prioritizing proposals was developed to illustrate how the selection process works, what types of data are required to characterize waste minimization activities, and who should participate in the selection process.

Some of the data required to evaluate proposals are readily available from the plant information management systems. However, much of the information must be based on the informed opinion of technical, financial, and policy personnel familiar with the proposed waste minimization activities and facilities. It is clearly impossible to remove all aspects of subjective judgment from the proposal selection process. With this important consideration in mind, the methodology presented in this report is put forth 10 enhance, not replace, the traditional DOE decision-making process.

The methodology was applied to a small set of proposed activities in a test case. Two waste minimization projects currently supporting changes to nuclear weapons 
manufacturing processes were investigated -- (1) the elimination of an acid rinsing process at the Rocky Flats Plant, and (2) the development and demonstration of a less hazardous potting material at the Pinellas Plant. The test case results demonstrate that it is possible to evaluate and prioritize proposed waste minimization activities in a systematic, defensible manner that enhances the existing DOE funding process.

Because of the limited number of proposals investigated in this project and the limited time available to document cost, risk, and benefit data, the test case results should not be taken as indicative of the merits of the specific proposals. Proposals are graded in relative terms based on many interpretations of the available information. Many data items (especially anticipated cost savings) could not be estimated for the test case. No attempt is made to determine whether the test case proposals are "good" or "bad" in a broad, absolute sense.

A set of evaluation criteria was developed to characterize the major issues associated with waste minimization within the DOE nuclear weapons complex. The evaluation criteria used in the test case provide a good outline of the concerns that should be considered in selecting proposals that offer the best trade-off's among cost, benefit, and risk issues. (It is important to note that cost alone is not an adequate measure for judging the merits of a proposal; other factors important to the DOE mission must be included in the evaluation criteria.)

A systematic means for developing relative proposal scores was demonstrated in the test case based on the evaluation criteria and the information collected. The scores are clearly related to the proposal data and the relative importance assigned to the evaluation criteria, providing an auditable record of the basis for proposal ranking.

A practical approach was also identified for selecting, from a ranked list of proposals, the combination that offers the maximum benefit to DOE at a cost that is within a specified budget. This approach, although not demonstrated in the test case, has been applied successfully to other DOE budget optimization issues.

Finally, we have presented a strategy for organizing a formal evaluation and prioritization process for DOE waste minimization proposals. Brief descriptions of the roles of the key individuals and groups that should participate in the process are provided.

The resuitis of the methodology development and application process were presented at the DOE Cost Model and Risk/Benefit Analysis Workshop to a cross section of personnel involved in waste minimization and waste management activities at many DOE sites. The working groups at the workshop generally agreed with the major elements of the methodology summarized above. While the working groups made several specific suggestions for improving the efficiency and utility of the methodology, no alternative method for proposal evaluation was suggested as a better way to support the DOE resource allocation process.

The following conclusions and recommendations are based on the refinements suggested at the DOE Cost Analysis and Risk/Benefit Workshop and the experience gained during the 
methodology development process and test case application.

1. The evaluation of waste minimization proposals can be based on a set of well-defined criteria.

2. The set of criteria developed in the test case provides a good starting point for the development of a comprehensive evaluation framework acceptable to the broad range of people who will be involved in the selection of waste minimization options.

3. Life cycle costs should be assessed in eviluating proposals; however, cost is not the only measure that should be considered in assessing the merits of proposed activities. Some factors important to the selection process cannot be expressed in monetary terms.

4. Net present value is the appropriate discounting method to use in evaluating the life cycle costs of proposals.

5. Data collection/documentation forms patterned after those used by EPA in its waste minimization opportunity evaluations provide an efficient means of systematically collecting and organizing the information needed to evaluate proposals. Many of the EPA forms can be adapted or expanded to accommodate DOE waste minimization proposal evaluation.

6. The structured evaluation criteria and evaluation process described in this report provide documented, defensible records to support the decision-making and resource allocation process. The reasons for ranking one proposal higher than another can be determined explicitly from the results of the evaluation. The use of the data collection forms described in the previous conclusion would further enhan this aspect of the approach.

7. A cost data base should be developed to support proposal preparation and evaluation. Data from pr'vious efforts should be collected and processed to provide a resource supporting future efforts. Guidance should be developed for cost estimation and for ensuring that sources of cost data used in proposals are identified adequately and that assessments are done properly.

8. The efficiency of the waste minimization proposal evaluation process can be improved by capturing more of the data required for the evaluation in the normal plant data systems. The plants are currently upgrading their hazardous materials and waste data management systems. It would be prudent to ensure that appropriate information is included in these upgrades to support the improved evaluation of waste minimization objectives.

9. An evaluation should be performed to determine the most appropriate technique for ranking proposals (e.g., analytic hierarchy process, multiattribute utility analysis) and for displaying results (e.g., single-number overall scores, graphic representations of top-level criteria scores).

10. A mechanism should be established to allow feedback from proposers and other participants in the selection process to ensure the continued 
improvement of the evaluation and prioritization process.

In summary, a comprehensive evaluation and prioritization methodology has been developed and tested. With relatively minor refinements, this methodology can be immediately useful to DOE Environmental Restoration and Waste Management and Defense Program organizations in preparing, evaluating, and prioritizing waste minimization proposals. 


\section{REFERENCES}

Decision Support Software Inc., 1989. Expert Choice Manual Version 7.0, Decision Support Software, McClean, VA.

DOE (U.S. Department of Energy), 1988a. "General Environmental Protection Program," Order 5400.1, U.S. Department of Energy, Washington, D.C.

DOE (U.S. Department of Energy), 1988b. "Waste Minimization Plan and Waste Reduction Reporting of DOE Hazardous, Radioactive, and Mixed Wastes," Implementation Guidance for Order 5400.1, U.S. Department of Energy, Washington, D.C.

DOE (U.S. Department of Energy), 1989a. "Environmental Restoration and Waste Management Five-Year Plan," DOE/S/0070, U.S. Department of Energy, Washington, D.C.

DOE (U.S. Department of Energy), 1989b. "Applied Research, Development, Demonstration, Testing and Evaluation Plan," U.S. Department of Energy, Washington, D.C.

EPA (U.S. Environmental Protection Agency), 1988. "Waste Minimization Opportunity Assessment Manual," EPA/625/7-88/003, U.S. Environmental Protection Agency, Cincinnati, $\mathrm{OH}$.

EPA (U.S. Environmental Protection Agency), 1989. "Pollution Prevention Benefits Manual" (Draft), U.S. Environmental Protection Agency, Washington, D.C.

Hockert, J. W., and B. L. Hulme, 1989. "Optimizing the Cost-Effectiveness of Risk Reduction," Proceedings of the International Topical Meeting on Probability, Reliability, and Safety Assessment, PSA '89, American Nuclear Society, Pittsburgh, PA.

Hulme, B. L., 1990. "Budget Allocation and the Analytical Hierarchy Process," SAND907091, Sandia National Laboratories, Albuquerque, New Mexico. 
APPENDIX A

Evaluation Criteria for Waste Minimization Proposals 


\section{PROPOSED OUTLINE OF EVALUATION CRITERIA \\ FOR WASTE MINIMIZATION PROPOSALS}

\section{ECONOMIC FEASIBILITY}

A. Cost Considerations

1. Life Cycle Cost (Net Present Value)

2. Individual Cost Elements

a. Implementation Costs

b. Post-Impl mentation Costs 'Savings)

B. Time Considerations

1. Total Implementation Time

2. Individual Time Elements

a. Research and Development Time

b. Certification Time

c. Facility Modification Time

${ }^{*}$ C. Cost and Schedule Uncertainty

\section{EFFECT ON ENVIRONMENTAL, SAFETY, AND HEALTH ISSUES}

A. Effect on Hazardcus Material and Waste Quantity

1. Hazardous Material Consumed

a. Specific Process

b. Entire Plant

2. Hazardous Waste Generated
a. Specific Process
b. Entire Plant

3. Hazardous Waste Stored On-site 


\section{PROPOSED OUTLINE OF EVALUATION CRITERIA FOR WASTE MINIMIZATION PROPOSALS}

B. Effect on Human Exposure

1. Workers
a. Normal Operations
b. Accident Conditions
c. Implementation

2. Public
a. Normal Operations
b. Accident Conditions

C. Effect on Material Hazard Level
1. Toxicity
2. Carcinogenicity
3. Mutagenicity
4. Flammability/Explosivity
5. Corrosivity
6. Activity Level

\section{EFFECT ON OPERATIONAL ISSUES}

A. Effect on Product Quality
1. Reliability
2. Safety
3. Testability
4. Maintainability

B. Effect on Processing Characteristics

1. Yield

2. Capacity

3. Availability

4. Safety

5. Implementation Downtime

6. Effect on Other Processes 


\section{PROPOSED OUTLINE OF EVALUATION CRITERIA FOR WASTE MINIMIZATION PROPOSALS}

\section{EFFECT ON INTANGIBLES}

A. Effect on Public Relations

1. Local Community

2. State Regulators

3. Federal Regulators

4. Congress

B. Effect on Management Effectiveness

1. Planning, Waste Monitoring, and Reporting

2. Cost Accountability

3. Periodic Inspections and Assessments

${ }^{*} \mathrm{C}$. Ethical Considerations

*D. Proximity to DOE Policy Goals

V. TECHNICAL RISK

A. Likelihood of Success

1. Dependency on Technological Advances or Breakthroughs

2. Availability of Key Personnel and Facilities

B. Research and Development Payoff

1. Application to Other DOE Issues

2. Application to General Industry

C. Consequence of Failure

1. Cost to Fix

a. Average Scenario

b. Severe Scenario 


\section{PROPOSED OUTLINE OF EVALUATION CRITERIA FOR WASTE MINIMIZATION PROPOSALS}

2. Operational Disruption
a. Average Scenario
b. Severe Scenario

3. Effect on Product Quality
a. Average Scenario
b. Severe Scenario

*Participants at the DOE Cost Model and Risk/Benefit Workshop suggested these additional evaluation criteria. These criteria were not used in the test case analysis. 
APPENDIX B

Summary Findings for Waste Minimization Proposals

B-1/B-2 


\section{SUMMARY FINDINGS}

ECONOMIC FEASIBILITY

COST CONSIDERATIONS

\section{(Evaluation Criterion I.A.1)}

1. The net present value (NPV) of all

life cycle costs associated with the proposal is:

$1=$ large, negative $(<-\$ 500,000)$

$2=$ negative $(-\$ 1000$ to $-\$ 500,000)$

$3=$ approximately zero (break even)

$4=$ positive $(\$ 1000$ to $\$ 500,000)$

$5=$ large, positive $(>\$ 50,000)$

Note: An estimate of NPV takes into account all identifiable costs (negative cash flows) that will be incurred, all incremental cost savings that will be gained (positive cash flows), and the timing of all cash flows. These cost considerations include those mentioned in Summary Findings \#2 and \#3 below.

(Evaluation Criterion I.A.2.a)

2. The total, discounted cost of the implementation phase of the proposal will be:

$$
\begin{aligned}
& 1=\text { very high }(>\$ 10,000,000) \\
& 2=\text { high }(\$ 5,000,000 \text { to } \$ 10,000,000) \\
& 3=\text { moderate }(\$ 1,000,000 \text { to } \$ 5,000,000) \\
& 4=\text { low }(\$ 500,000 \text { to } \$ 1,000,000) \\
& 5=\text { very low }(<\$ 500,000)
\end{aligned}
$$

Note: Implementation costs include all costs that will occur from the proposal initiation/option evaluation phase of the project to preparing existing operating facilities to accept the anticipated process changes. Implementation costs normally include the cost of research and development, verification, and facility modification. 


\section{SUMMARY FINDINGS \\ ECONOMIC FEASIBILITY \\ COS'T CONSIDERATIONS (Continued)}

(Evaluation Criterion I.A.2.b)

3. The effect the proposal will have on the annual operating costs to DOE will be:

$$
\begin{aligned}
& 1=\text { large losses }(<-\$ 50,000 / \text { year }) \\
& 2=\text { moderate losses }(\$ 1000 \text { to }-\$ 50,000 / \text { year }) \\
& 3=\text { approximately } \$ 0 / \text { year } \\
& 4=\text { moderate savings }(\$ 1000 \text { to } \$ 50,000 / \text { year }) \\
& 5=\text { large savings }(>\$ 50,000 / \text { year })
\end{aligned}
$$

Note: Average annual cost savings (or losses) represent an estimate of the average yearly increment in operating, testing, and other less tangible expenses that DOE will experience if the proposal is successfully implemented. Average annual cost savings (losses) are discounted using present value techniques to account for the time value of money. 


\section{SUMMARY FINDINGS}

ECONOMIC FEASIBILITY

TIME CONSIDERATIONS

(Evaluation Criterion I.B.1)

4. The total length of time required to complete all phases of the proposal will be:

$1=$ greater than 10 years

$2=6$ to 10 years

$3=3$ to 6 years

$4=1$ to 3 years

$5=$ less than 1 year

(Evaluation Criterion I.B.2.a)

5. The length of time required to perform research, development, and testing activities will be:

$1=$ greater than 6 years

$2=4$ to 6 years

$3=2$ to 4 years

$4=1$ to 2 years

$5=$ less than 1 year

(Evaluation Criterion I.B.2.b)

6. The length of time required to perform verification testing to certify producis from the modified manufacturing line will be:

$1=$ greater than 6 years

$2=4$ to 6 years

$3=2$ to 4 years

$4=1$ to 2 years

$5=$ less than 1 year 


\section{SUMMARY FINDINGS}

\section{ECONOMIC FEASIYILITY \\ TIME CONSIDERATIONS (Continued)}

(Evaluation Criterion I.B.2.c)

7. The length of time required to perform facility modifications to accomodate the proposal will be:

$$
\begin{aligned}
& 1=\text { greater than } 2 \text { years } \\
& 2=1 \text { to } 2 \text { years } \\
& 3=6 \text { months to } 1 \text { year } \\
& 4=3 \text { to } 6 \text { months } \\
& 5=\text { less than } 3 \text { months }
\end{aligned}
$$




\section{SUMMARY FINDINGS}

EFFECT ON ENVIRONMENTAL, SAFETY, AND HEALTH ISSUES EFFECT ON HAZARDOUS MATERIAL AND WASTE QUANTITY

If the proposal is successfully implemented:

(Evaluation Criterion II.A.1.a)

8. The rate at which the specific process generates hazardous waste will:

$1=$ increase significantly $(>25 \%)$

$2=$ increase moderately ( $5 \%$ to $25 \%$ )

$3=$ stay the same

$4=$ decrease moderately (5\% to $25 \%)$

$5=$ decrease significantly $(>25 \%)$

(Evaluation Criterion II.A.1.b)

9. The rate at which the entire facility

generates hazardous waste will:

$1=$ increase significantly $(>25 \%)$

$2=$ increase moderately ( $5 \%$ to $25 \%$ )

$3=$ stay the same

$4=$ decrease moderately $(5 \%$ to $25 \%)$

$5=$ decrease significantly $(>25 \%)$

(Evaluation Criterion II.A.2.a)

10. The rate at which the specific process consumes hazardous material will:

$1=$ increase significantly $(>25 \%)$

$2=$ increase moderately ( $5 \%$ to $25 \%$ )

$3=$ stay the same

$4=$ decrease moderately $(5 \%$ to $25 \%)$

$5=$ decrease significantly $(>25 \%)$ 


\section{SUMMARY FINDINGS}

EFFECT ON ENVIRONMENTAL, SAFETY, AND HEALTH ISSUES EFFECT ON HAZARDOUS MATERIAL AND WASTE QUANTITY (Continued)

If the proposal is successfully implemented:

(Evaluation Criterion II.A.2.b)

11. The rate at which the entire facility

consumes hazardous material will:

$1=$ increase significantly $(>25 \%)$

$2=$ increase moderately ( $5 \%$ to $25 \%$ )

$3=$ stay the same

$4=$ decrease moderately (5\% to $25 \%)$

$5=$ decrease significantly $(>25 \%)$

(Evaluation Criterion II.A.3)

12. The rate at which hazardous waste must be stored on-site at the facility will:

$1=$ increase significantly

$2=$ increase slightly

$3=$ stay the same (not applicable)

$4=$ decrease slightly

$5=$ decrease significantly 


\section{EFFECT ON ENVIRONMENTAL, SAFETY, AND HEALTH ISSUES EFFECT ON HUMAN EXPOSURE}

If the proposal is successfully implemented:

(Evaluation Criterion Il.B.1.a)

13. The number of workers exposed to hazardous material and waste during normal operations will:

$1=$ increase significantly

$2=$ increase slightly

$3=$ stay the same (not applicable)

$4=$ decrease slightly

$5=$ decrease significantly

(Evaluation Criterion II.B.1.b)

14. The number of workers exposed to hazardous material and waste during postulated accident conditions will:

$1=$ increase significantly

$2=$ increase slightly

$3=$ stay the same (not applicable)

$4=$ decrease slightly

$5=$ decrease significantly

(Evaluation Criterion II.B.1.c)

15. The level of worker contact to hazardous material and waste during the implementation phase of the proposal will result in:

$1=$ extreme exposure

$2=$ large exposure

$3=$ moderate exposure

$4=$ small exposure

$5=$ essentially no exposure 


\section{SUMMARY FINDINGS}

\section{EFFECT ON ENVIRONMENTAL, SAFETY, AND HEALTH ISSUES EFFECT ON HUMAN EXPOSURE (Continued)}

If the proposal is successfully implemented:

(Evaluation Criterion II.B.2.a)

16. The level of public exposure to hazardous material and waste during normal operations will:

$1=$ increase significantly

$2=$ increase slightly

$3=$ stay the same (not applicable)

$4=$ decrease slightly

$5=$ decrease significantly

(Evaluation Criterion II.B.2.b)

17. The level of public exposure to hazardous material and waste during postulated accident conditions will:

$1=$ increase significantly

$2=$ increase slightly

$3=$ stay the same (not applicable)

$4=$ decrease slightly

$5=$ decrease significantly

\section{$\begin{array}{lllll}1 & 2 & 3 & 4 & 5\end{array}$}

$\begin{array}{lllll}1 & 2 & 3 & 4 & 5\end{array}$ 


\section{SUMMARY FINDINGS}

\section{EFFECT ON ENVIRONMENTAL, SAFETY, AND HEALTH ISSUES EFFECT ON MATERIAL HAZARD L.EVEL}

If the proposal is successfully implemented:

(Evaluation Criterion II.C.1)

18. The overall toxicity of the hazardous material(s) used in the process(es)

will:

$1=$ increase significantly

$2=$ increase slightly

$3=$ stay the same (not applicable)

$4=$ decrease slightly

$5=$ decrease significantly

(Evaluation Criterion II.C.2)

19. The overall carcinogenicity of the hazardous material(s) used in the process(es) will:

$1=$ increase significantly

$2=$ increase slightly

$3=$ stay the same (not applicable)

$4=$ decrease slightly

$5=$ decrease significantly

(Evaluation Criterion II.C.3)

20. The overall mutagenicity of the hazardous material(s) used in the process(es) will:

$1=$ increase significantly

$2=$ increase slightly

$3=$ stay the same (not applicable)

$4=$ decrease slightly

$5=$ decrease significantly 


\section{SUMMARY FINDINGS}

\section{EFFECT ON ENVIRONMENT A., SAFETY, AND HEALTH ISSUES EFFECT ON MATERIAL HAZARD LEVEL (Continued)}

If the proposal is successfully implemented:

(Evaluation Criterion II.C.4)

21. The overall flammability/explosivity characteristics of the hazardous material(s) used in the process(es) will:

$1=$ increase significantly

$2=$ increase slightly

$3=$ stay the same (not applivable)

$4=$ decrease slightly

$5=$ decrease significr.ntly

(Evaluation Criterion II.C.5)

22. The overa!! corrosivity of the hazardous material(s) used in the process(es) will:

$1=$ increase significantly

$2=$ increase slightly

$3=$ stay the same (not applicable)

$4=$ decrease slightly

$5=$ decrease significantly

(Evaluation Criterion II.C.6)

23. The overall activity level of the hazardous material(s) used in the process(es) will:

$1=$ increase significantly

$2=$ increase slightly

$3=$ stay the same (not applicable)

$4=$ decrease slightly

$5=$ decrease significantly 


\section{SUMMARY FINDINGS}

\section{EFFECT ON OPERATIONAL ISSUES EFFECT ON PRODUCT QUALITY}

If the proposal is successfully implemented:

(Evaluation Criterion III.A.1)

24. The reliability of the ultimate product(s) provided by the DOE facilities involved in the proposal will:

$1=$ decrease significantly

$2=$ decrease slightly

$3=$ stay the same (not applicable)

$4=$ increase slightly

$5=$ increase significantly

(Evaluation Criterion III.A.2)

25. The safety of the ultimate product(s) provided by the DOE facilities involved in the proposal will:

$1=$ decrease significantly

$2=$ decrease slightly

$3=$ stay the same (not applicable)

$4=$ increase slightly

$5=$ increase significantly

(Evaluation Criterion III.A.3)

26. The testability of the ultimate product(s) provided by the DOE facilities involved in the proposal will:

$1=$ decrease significantly

$2=$ decrease slightly

$3=$ stay the same (not applicable)

$4=$ increase slightly

$5=$ increase significantly 


\section{SUMMARY FINDINGS \\ EFFECT ON OPERATIONAL ISSUES \\ EFFECT ON PRODUCT QUALITY (Continued)}

If the proposal is successfully implemented:

(Evaluation Criterion III.A.4)

27. The maintainability of the ultimate product(s) provided by the DOE facilities involved in the proposal

will:

$1=$ decrease significantly

$2=$ decrease slightly

$3=$ stay the same (not applicable)

$4=$ increase slightly

$5=$ increase significantly 


\section{SUMMARY FINDINGS}

EFFECT ON OPERATIONAL ISSUES

EFFECT ON PROCESSING CHARACTERISTICS

If the proposal is successfully implemented:

(Evaluation Criterion III.B.1)

28. The operating yield of the process(es) involved in the proposal

will:

$1=$ decrease significantly

$2=$ decrease slightly

$3=$ stay the same (not applicable)

$4=$ increase slightly

$5=$ increase significantly

(Evaluation Criterion III.B.2)

29. The operating capacity of the process(es) involved in the proposal will:

$1=$ decrease significantly

$2=$ decrease slightly

$3=$ stay the same (not applicable)

$4=$ increase slightly

$5=$ increase significantly

(Evaluation Criterion III.B.3)

30. The operating availability of the process(es) involved in the proposal will:

$1=$ decrease significantly

$2=$ decrease slightly

$3=$ stay the same (not applicable)

$4=$ increase slightly

$5=$ increase significantly 


\section{SUMMARY FINDINGS \\ EFFECT ON OPERATIONAL ISSUES \\ EFFECT ON PROCESSING CHARACTERISTICS (Continued)}

If the proposal is successfully implemented:

(Evaluation Criterion III.B.4)

31. The operating safety of the process(es) involved in the proposal

will:

$1=$ decrease significantly

$2=$ decrease slightly

$3=$ stay the same (not applicable)

$4=$ increase slightly

$5=$ increase significantly

(Evaluation Criterion III.B.5)

32. How long must the process(es) be halted to implement the proposal?

$1=$ extreme outage ( $>6$ months)

$2=$ major outage ( 3 to 6 months)

$3=$ moderate outage ( 1 to 3 months)

$4=$ minor outage $(<1$ month $)$

$5=$ not at all

(Evaluation Criterion III.B.6)

33. The effect of the change on other processes at the plant and other DOE facilities with respect to issues such as compatibility, burden shifting (waste management responsibilities), and processing outages will be:

$1=$ potentially large problems

$2=$ potentially small problems

$3=$ no perceived problems or benefits

$4=$ potentially small benefits

$5=$ potentially large benefits $\begin{array}{lllll}1 & 2 & 3 & 4 & 5\end{array}$

$\begin{array}{lllll}1 & 2 & 3 & 4 & 5\end{array}$ 


\section{SUMMARY FINDINGS \\ EFFECT ON INTANGIBLES \\ EFFECT ON PUBLIC RELATIONS}

If the proposal is successfully implemented:

(Evaluation Criterion IV.A.1)

34. Relations between the DOE facility

and the local community will:

$1=$ worsen dramatically

$2=$ worsen marginally

$3=$ stay the same (not applicable)

$4=$ improve marginally

$5=$ improve dramatically

(Evaluation Criterion IV.A.2)

35. Relations between the DOE facility

and state regulatory agencies will:

$1=$ worsen dramatically

$2=$ worsen marginally

$3=$ stay the same (not applicable)

$4=$ improve marginally

$5=$ improve dramatically

(Evaluation Criterion IV.A.3)

36. Relations between the DOE facility

and federal regulatory agencies will:

$1=$ worsen dramatically

$2=$ worsen marginally

$3=$ stay the same (not applicable)

$4=$ improve marginally

$5=$ improve dramatically 


\section{SUMMARY FINDINGS \\ EFFECT ON INTANGIBLES \\ EFFECT ON PUBLIC RELATIONS (Continued)}

If the proposal is successfully implemented:

(Evaluation Criterion IV.A.4)

37. Relations between the DOE facility

$\begin{array}{lllll}1 & 2 & 3 & 4 & 5\end{array}$

and the Congress will:

$1=$ worsen dramatically

$2=$ worsen marginally

$3=$ stay the same (not applicable)

$4=$ improve marginally

$5=$ improve dramatically 


\section{SUMMARY FINDINGS}

EFFECT ON INTANGIBLES

EFFECT ON MANAGEMENTT EFFECTIVENESS

If the proposal is successfully implemented:

(Evaluation Criterion IV.B.1)

38. The ability of the DOE facility to perform planning, waste monitoring, and reporting activities will:

$1=$ decrease significantly

$2=$ decrease slightly

$3=$ stay the same (not applicable)

$4=$ increase slightly

$5=$ increase significantly

(Evaluation Criterion IV.B.2)

39. The ability of the DOE facility to allocate costs to specific budget items (i.e., cost accountability) will:

$1=$ decrease significantly

$2=$ decrease slightly

$3=$ stay the same (not applicable)

$4=$ increase slightly

$5=$ increase significantly

(Evaluation Criterion IV.B.3)

40. The ability of the DOE facility to respond favorably to periodic inspections and assessments will:

$1=$ decrease significantly

$2=$ decrease slightly

$3=$ stay the same (not applicable)

$4=$ increase slightly

$5=$ increase significantly

\section{$\begin{array}{lllll}1 & 2 & 3 & 4 & 5\end{array}$}




\section{SUMMARY FINDINGS}

TECHNICAL RISK

\section{LIKELIHOOD OF SUCCESS}

(Evaluation Criterion V.A.1)

41. To what extent does the successful

outcome of the proposal depend on

technological advances or

breakthroughs?

$1=$ significant advances required

$2=$ undemonstrated but some engineering principles

understood

$3=$ undemonstrated but engineering principles well understood

$4=$ basic concept demonstrated elsewhere

$5=$ thoroughly demonstrated in similar applications

(Evaluation Criterion V.A.2)

42. To what extent does the successful outcome of the proposal depend on the timely availability of key personnel and facilities?

$1=$ availability of personnel and facility resources highly uncertain

$2=$ availability of personnel and facility resources uncertain

$3=$ personnel and facility resources probably available

$4=$ personnel and facility resources most likely available

$5=$ highly certain that personnel and facility resources will be available 


\section{SUMMARY FINDINGS}

TECHNICAL RISK

RESEARCH AND DEVELOPMENT PAYOFF

If the proposal is successfully implemented:

(Evaluation Criterion V.B.1)

43. Will the research and development insights gained from this proposal be applicable to other activities within DOE?

$1=$ not applicable

$2=$ remotely applicable

$3=$ slightly applicable

$4=$ moderately applicable

$5=$ highly applicable

(Evaluation Criterion V.B.2)

44. Will the research and development insights gained from this proposal be applicable to commercial industry?

$1=$ not applicable

$2=$ remotely applicable

$3=$ slightly applicable

$4=$ moderately applicable

$5=$ highly applicable 
SUMMARY FINDINGS

TECHNICAL RISK

CONSEQUENCE OF FAILURE

Assuming that the proposal is implemented but falls unexpectedly at a later date:

(Evaluation Criterion V.C.1.a)

45. The level of resources that would be required to analyze the failure, implement a fix, verify the change, and repair/replace existing products, assuming an average scenario, would be:

$1=$ extremely high

$2=$ high

$3=$ moderate

$4=$ small

$5=$ very small

(Evaluation Criterion V.C.1.b)

46. The level of resources that would be required to analyze the failure, implement a fix, verify the change, and repair/replace existing products, assuming a severe scenario, would be:

$1=$ extremely high

$2=$ high

$3=$ moderate

$4=$ small

$5=$ very small 


\section{SUMMARY FINDINGS}

TECHNICAL RISK

CONSEQUENCE OF FAILURE (Continued)

Assuming that the proposal is implemented but fails unexpectedly at a later date:

(Evaluation Criterion V.C.2.a)

47. The level of production disruption that would occur while the failure is being remedied, assuming an average scenario, would be:

$1=$ extremely severe ( $>3$ years)

$2=$ severe $(1$ to 3 years $)$

$3=$ large $(6$ months to 1 year $)$

$4=$ moderate ( 3 to 6 months)

$5=\operatorname{small}(<3$ months $)$

(Evaluation Criterion V.C.2.b)

48. The level of production disruption that would occur while the failure is being remedied, assuming a severe scenario, would be:

$1=$ extremely severe ( $>3$ years)

$2=$ severe (1 to 3 years $)$

$3=$ large ( 6 months to 1 year)

$4=$ moderate $(3$ to 6 months $)$

$5=\operatorname{small}(<3$ months $)$ 


\section{SUMMARY FINDINGS}

\section{TECHINICAL RISK \\ CONSEQUENCE OF FAILURE (Continued)}

Assuming that the proposal is implemented but fails unexpectedly at a later date:

(Evaluation Criterion V.C.3.a)

49. The effect that the failure would have on product quality, assuming an average scenario, would be:

$1=$ extreme negative effect

$2=$ large negative eifect

$3=$ moderate negative effect

$4=$ small negative effect

$5=$ no effect

(Evaluation Criterion V.C.3.b)

50. The effect that the failure would have on produrt quality, assuming a severe scenario, would be:

$1=$ extreme negative effect

$2=$ large negative effect

$3=$ moderate negative effect

$4=$ small negative effect

$5=$ no effect $\begin{array}{lllll}1 & 2 & 3 & 4 & 5\end{array}$

$\begin{array}{lllll}1 & 2 & 3 & 4 & 5\end{array}$ 


\section{APPENDIX C}

Summary Findings for Rocky Flats Plant Test Case Study

C-1/C-2 


\section{$\underline{\text { Rocky Flats Results }}$}

\section{SUMMARY FINDINGS}

\section{ECONOMIC FEASIBILITY

COST CONSIDERATIONS

(Evaluation Criterion I.A.1)

1. The net present value (NPV) of all

life cycle costs associated with the

1 (2) 345 proposal is:

$$
\begin{aligned}
& 1=\text { large, negative }(<-\$ 500,000) \\
& 2=\text { negative }(-\$ 1000 \text { to }-\$ 500,000) \\
& 3=\text { approximately zero }(\text { break even }) \\
& 4=\text { positive }(\$ 1000 \text { to } \$ 500,000) \\
& 5=\text { large, positive }(>\$ 500,000)
\end{aligned}
$$

Comment: $\approx-\$ 425,000 @ 10 \%$

$$
\begin{aligned}
& \approx-\$ 428,000 @ 8 \% \\
& \approx-\$ 412,000 @ 6 \%
\end{aligned}
$$

(See NPV diagram given in Figure 5-2. Note that many of the cost savings attributable to the proposal could not be identified for the test case.)

(Evaluation Criterion I.A.2.a)

2. The total, discounted cost of the implementation phase of the proposal will be:

$$
\begin{aligned}
& 1=\text { very high }(>\$ 10,000,000) \\
& 2=\text { high }(\$ 5,000,000 \text { to } \$ 10,000,000) \\
& 3=\text { moderate }(\$ 1,000,000 \text { to } \$ 5,000,000) \\
& 4=\text { low }(\$ 500,(0) 0 \text { to } \$ 1,000,000) \\
& 5=\text { very low }(<\$ 5(0), 000)
\end{aligned}
$$

Comment:-\$582,000@10\%

-\$646,000@8\%

$-\$ 719,000 @ 6 \%$

(See NPV diagram given in Figure 5-2. These discomnted figures represent the NPV of all costs that will be experienced before the proposal is complete and successfully implemented.) 
Rocky Flats Results

SUMMARY FINDINGS

ECONOMIC FEASIBILITY

COST CONSIDERATIONS (Continued)

(Evaluation Criterion I.A.2.b)

3 The effect the proposal will have on the annual operating costs to DOE will be:

$1=$ large losses $(<-\$ 50,000 /$ year $)$

$2=$ moderate losses $(-\$ 1000$ to $-\$ 50,000 /$ year $)$

$3=$ approximately $\$ 0 /$ year

$4=$ moderate savings ( $\$ 1000$ to $\$ 50,000 /$ year $)$

$5=$ large savings $(>\$ 50,000 /$ year $)$

Comment: \$40,000/year@10\%

$\$ 35,000 / y e a r @ 8 \%$

$\$ 30,000$ year @ 6\%

(See NPV diagram given in Figure 5-2. The figures listed above are derived taking into account the $\$ 57,000$ per year savings and the periodic costs for a shelf life storage program (SLS). Cost savings are inflated @ 4\% per year and $S L S$ costs are not. The average costs represent the present value "payments" that Rocky Flats would experience due to the inherent cost savings of the proposal. Also note that many of the cost savings attributable to this proposal could not be identified for the test case.) 
Rocky Flats Results

\section{SUMMARY FINDINGS}

\section{ECONOMIC FEASIBILITY}

\section{TIME CONSIDERATIONS}

(Evaluation Criterion I.B.1)

4. The total length of time required to complete all phases of the proposal

will be:

$1=$ greater than 10 years

$2=6$ to 10 years

$3=3$ to 6 years

$4=1$ to 3 years

$5=$ less than 1 year

Comment: 7 years (see NPV timeline given in Figure 5-2)

(Evaluation Criterion I.B.2.a)

5. The length of time required to perform research, development, and testing activities will be:

$1=$ greater than 6 years

$2=4$ to 6 years

$3=2$ to 4 years

$4=1$ to 2 years

$5=$ less than 1 year

Comment: 6 years (see NPV timeline given in Figure 5-2)
1 (2) 3445 


\section{Rocky Flats Results}

\section{SUMMARY FINDINGS \\ ECONOMIC FEASIBILITY \\ TIME CONSIDERATIONS (Continued)}

(Evaluation Criterion I.B.2.b)

6. The length of time required to perform verification testing to certify products from the modified manufacturing line will be:

$$
\begin{aligned}
& 1=\text { greater than } 6 \text { years } \\
& 2=4 \text { to } 6 \text { years } \\
& 3=2 \text { to } 4 \text { years } \\
& 4=1 \text { to } 2 \text { years } \\
& 5=\text { less than } 1 \text { year }
\end{aligned}
$$

Comment: 1 year (see NPV timeline given in Figure 5-2.)

(Evaluation Criterion I.B.2.c)

7. The length of time required to perform facility modifications to accomodate the proposal will be:

$1=$ greater than 2 years

$2=1$ to 2 years

$3=6$ months to 1 year

$4=3$ to 6 months

$5=$ less than 3 months

Comment: Essentially no time is required for facility modifications. 
Rocky Flats Results

SUMMARY FINDINGS

\section{EFFECT ON ENVIRONMENTAL, SAFETY, AND HEALTH ISSUES EFFECT ON HAZARDOUS MATERIAL AND WASTE QUANTITY}

If the proposal is successfully implemented:

(Evaluation Criterion II.A.1.a)

8. The rate at which the specific process generates hazardous waste will:

$1=$ increase significantly $(>25 \%)$

$2=$ increase moderately ( $5 \%$ to $25 \%)$

$3=$ stay the same

$4=$ decrease moderately ( $5 \%$ to $25 \%)$

$5=$ decrease significantly $(>25 \%)$

Comment: Process change will save 800,000 gallons of hazardous acid waste annually. 15 million gallons of hazardous acid waste generated at Rocky Flats annually. Process change will completely eliminate acid in process.

(Evaluation Criterion II.A.1.b)

9. The rate at which the entire facility generates hazardous waste will:

$1=$ increase significantly $(>25 \%)$

$2=$ increase moderately ( $5 \%$ to $25 \%)$

$3=$ stay the same

$4=$ decrease moderately $(5 \%$ to $25 \%)$

$5=$ decrease significantly $(>25 \%)$

Comment: Proposed savings very small with respect to entire plant hazardous waste. 
Rocky Flats Results

SUMMARY FINDINGS

EFFECT ON ENVIRONMENTAL, SAFETY, AND HEALTH ISSUES

EFFECT ON HAZARDOUS MATERIAL AND WASTE QUANTITY (Continued)

If the proposal is successfully implemented:

(Evaluation Criterion II.A.2.a)

10. The rate at which the specific

process consumes hazardous material

$\begin{array}{lllll}1 & 2 & 3 & 4 & (5)\end{array}$

will:

$1=$ increase significantly $(>25 \%)$

$2=$ increase moderately ( $5 \%$ to $25 \%)$

$3=$ stay the same

$4=$ decrease moderately (5\% to $25 \%)$

$5=$ decrease significantly $(>25 \%)$

Comment: Completely eliminate acid use in process (2000 gallons/year).

(Evaluation Criterion II.A.2.b)

11. The rate at which the entire facility consumes hazardous material will:

$1=$ increase significantly $(>25 \%)$

$2=$ increase moderately ( $5 \%$ to $25 \%$ )

$3=$ stay the same

$4=$ decrease moderately $(5 \%$ to $25 \%)$

$5=$ decrease significantly $(>25 \%)$

Comment: Very small compared to overall plant volume. 
$\underline{\text { Rocky Flats Results }}$

\section{SUMMARY FINDINGS}

EFFECT ON ENVIRONMENTAL, SAFETY, AND HEALTH ISSUES EFFECT ON HAZARDOUS MATERIAL AND WASTE QUANTITY (Continued)

If the proposal is successfully implemented:

(Evaluation Criterion II.A.3)

12. The rate at which hazardous waste must be stored on-site at the facility will:

$$
\begin{aligned}
& 1=\text { increase significantly } \\
& 2=\text { increase slightly } \\
& 3=\text { stay the same (not applicable) } \\
& 4=\text { decrease slightly } \\
& 5=\text { decrease significantly }
\end{aligned}
$$

Comment: Acil sent to 700 area, mixed with Pu acid waste, stored as mixed waste (circus tents). Mixed waste drums will accumulate at a slower rate. 
Rocky Flats Results

SUMMARY FINDINGS

EFFECT ON ENVIRONMENTAL, SAFETY, AND HEALTH ISSUES

EFFECT ON HUMAN EXPOSURE

If the proposal is successfully implemented:

(Evaluation Criterion II.B.1.a)

13. The number of workers exposed to hazardous material and waste during

normal operations will:

$1=$ increase significantly

$2=$ increase slightly

$3=$ stay the same (not applicable)

$4=$ decrease slightly

$5=$ decrease significantly

Comment: Eliminate acid.

(Evaluation Criterion II.B.1.b)

14. The number of workers exposed to hazardous material and waste during postulated accident conditions will:

$1=$ increase significantly

$2=$ increase slightly

$3=$ stay the same (not applicable)

$4=$ decrease slightly

$5=$ decrease significantly

Comment: Eliminate acid. 
Rocky Flats Results

\section{SUMMARY FINDINGS}

\section{EFFECT ON ENVIRONMENTAL, SAFETY, AND HEALTH ISSUES EFFECT ON HUMAN EXPOSURE (Continued)}

If the proposal is successfully implemented:

(Evaluation Criterion II.B.1.c)

15. The level of worker contact to hazardous material and waste during the implementation phase of the proposal will result in:

$1=$ extreme exposure

$2=$ large exposure

$3=$ moderate exposure

$4=$ small exposure

$5=$ essentially no exposure

Comment: Very small exposure involved in draining acid and replacing with deiengent.

(Evaluation Criterion II.B.2.a)

16. The level of public exposure to hazardous material and waste during normal operations will:

$1=$ increase significantly

$2=$ increase slightly

$3=$ stay the same (not applicable)

$4=$ decrease slightly

$5=$ decrease significantly

Comment: No appreciable public risk under normal operations; therefore, no change in exposure to public. 


\section{Rocky Flats Results}

\section{SUMMARY FINDINGS}

\section{EFFECT ON ENVIRONMENTAL, SAFETY, AND HEALTH ISSUES EFFECT ON HUMAN EXPOSURE (Continued)}

If the proposal is successfully implemented:

(Evaluation Criterion II.B.2.b)

17. The level of public exposure to hazardous material and waste during

postulated accident conditions will:

$1=$ increase significantly

$2=$ increase slightly

$3=$ stay the same (not applicable)

$4=$ decrease slightly

$5=$ decrease significantly

Comment: Reduce risk of acid spill (exterior tank) to zero if acid is removed from the process. 


\section{Rocky Flats Results}

\section{SUMMARY FINDINGS}

\section{EFFECT ON ENVIRONMENTAL, SAFETY, AND HEALTH ISSUES EFFECT ON MATERIAL HAZARD LEVEL}

If the proposal is successfully implemented:

(Evaluation Criterion II.C.1)

18. The overall toxicity of the hazardous material(s) used in the process(es)

will:

$1=$ increase significantly

$2=$ increase slightly

$3=$ stay the same (not applicable)

$4=$ decrease slightiy

$5=$ decrease significantly

Comment: Detergent not toxic.

(Evaluation Criterion II.C.2)

19. The overall carcinogenicity of the hazardous material(s) used in the process(es) will:

$1=$ increase significantly

$2=$ increase slightly

$3=$ stay the same (not applicable)

$4=$ decrease slightly

$5=$ decrease significantly

Comment: Acid and detergent not carcinogenic. 
Rocky Flats Results

SUMMARY FINDINGS

EFFECT ON ENVIRONMENTAL, SAFETY, AND HEALTH ISSUES

EFFECT ON MATERIAL HAZARD LEVEL (Continued)

If the proposal is successfully implemented:

(Evaluation Criterion II.C.3)

20. The overall mutagenicity of the hazardous material(s) used in the process(es) will:

$1=$ increase significantly

$2=$ increase slightly

$3=$ stay the same (not applicable)

$4=$ decrease slightly

$5=$ decrease significantly

Comment: Acid and detergent not muagenic.

(Evaluation Criterion II.C.4)

21. The overall flammability/explosivity

characteristics of the hazardous

12 (3) $4 \quad 5$

material(s) used in the process(es)

will:

$1=$ increase significantly

$2=$ increase slightly

$3=$ stay the same (not applicable)

$4=$ decrease slightly

$5=$ decrease significantly

Comment: Acid and detergent not flammable. 
Rocky Fluts Results

SUMMARY FINDINGS

EFFECT ON ENVIRONMENTAL, SAFETY, AND HEAL'TH ISSUES EFFECT ON MATERIAL HAZARD LEVEL (Continued)

If the proposal is successfully implemented:

(Evaluation Criterion II.C.5)

22. The overall corrosivity of the hazardous material(s) used in the

process(es) will:

$1=$ increase significantly

$2=$ increase slightly

$3=$ stay the same (not applicable)

$4=$ decrease slightly

$5=$ decrease significantly

Comment: Detergent not corrosive.

(Evaluation Criterion II.C.6)

23. The overall activity level of the hazardcias material(s) used in the process(es) will:

$1=$ increase significantiy

$2=$ increase slightly

$3=$ stay the same (not applicable)

$4=$ decrease slightly

$5=$ decrease significantly

Comment: $N / A$. 
Rocky Flats Results

SUMMARY FINDINGS

EFFECT ON OPERATIONAL REQUIREMENTS

EFFECT ON PRODUCT QUALITY

If the proposal is successfully implemented:

(Evaluation Criterion Iil.A.1)

24. The relial ility of the ultimate product(s) provided by the DOE

facilities involved in the proposal

will:

$1=$ decrease significantly

$2=$ decrease slightly

$3=$ staly the same (not applicable)

$4=$ increase slightly

$5=$ increase significantly

C.mment: Weld worthiness, permeability should not be affected.

(Evaluation Criterion III.A.2)

25. The safety of the ultimate product(s)

12 (3) 4 provided by the DOE facilities

involved in the proposal will:

$1=$ decrease significantly

$2=$ decrease slightly

$3=$ stay the same (not applicable)

$4=$ increase slightly

$5=$ increase significantly

Comment: Leak tightmess should not be affected. 
Rocky Flats Results

SUMMARY FINDINGS

EFFECT ON OPERATIONAL REQUIREMENTS

EFFECT ON PRODUCT QUALITY (Continued)

If the proposal is successfully implemented:

(Evaluation Criterion III.A.3)

26. The testability of the unimate product(s) provided by the DOE facilities involved in the proposal will:

$1=$ decrease significantly

$2=$ decrease slightly

$3=$ stay the same (not applicable)

$4=$ increase slightly

$5=$ increase significantly

Comment: Tested through shelf storage.

(Evaluation Criterion III.A.4)

27. The maintainability of the ultimate product(s) provided by the DOE facilities involved in the proposal will:

$1=$ decrease significantly

$2=$ decrease slightly

$3=$ stay the same (not applicable)

$4=$ increase slightly

$5=$ increase significantly

Comment: Maintainability (change-out) not affected by detergent rinse. 
Rocky Flats Results

SUMMARY FINDINGS

EFFECT ON OPERATIONAL FEQUIREMENTS

EFFECT ON PROCESSING CHARACTERISTICS

If the proposal is successfully implemented:

(Evaluation Criterion III.B.1)

28. The operating yield of the

process(es) involved in the proposal

will:

$1=$ decrease significantly

$2=$ decrease slightly

$3=$ stay the same (not applicable)

$4=$ increase slightly

$5=$ increase significantly

Comment: Yield should not be affected.

(Evaluation Criterion III.B.2)

29. The operating capacity of the process(es) involved in the proposal

will:

$1=$ decrease significantly

$2=$ decrease slightly

$3=$ stay the same (not applicable)

$4=$ increase slightly

$5=$ increase significantly

Comment: Capacity should not be affec" d. 


\section{Rocky Flats Results \\ SUMMARY FINDINGS \\ EFFECT ON OPERATIONAL REQUIREMENTS EFFECT ON PROCESSING CHARACTERISTICS (Continued)}

If the proposal is successfully implemented:

(Evaluation Criterion III.B.3)

30. The operating availability of the process(es) involved in the proposal will:

$1=$ decrease significantly

$2=$ decrease slightly

$3=$ stay the same (not applicable)

$4=$ increase slightly

$5=$ increase significantly

Comment: Availability should not be affected.

(Evaluation Criterion III.B.4)

31. The operating safeiy of the process(es) involved in the proposal

will:

$1=$ decrease significantly

$2=$ decrease slightly

$3=$ stay the same (not applicable)

$4=$ increase slightly

$5=$ increase significantly

Comment: No acid spills or worker contact to worry about. 
Rocky Flats Results

\section{SUMMARY FINDINGS}

\section{EFFECT ON OPERATIONAL REQUIREMENTS EFFECT ON PROCESSING CHARACTERISTICS (Continued)}

If the proposal is successfully implemented:

(Evaluation Criterion III.B.5)

32. How long must the process(es) be

halted to implement the proposal?

$\begin{array}{llll}1 & 2 & 3 & 4\end{array}$

$1=$ extreme outage $(>6$ months $)$
$2=$ major outage $(3$ to 6 months $)$
$3=$ moderate outage $(1$ to 3 months $)$
$4=$ minor outage $(<1$ month $)$
$5=$ not at all

Comment: Essentially no time.

(Evaluation Criterion III.B.6)

33. The effect of the change on other processes at the plant and other DOE facilities with respect to issues such as compatibility, burden shifting (waste management responsibilities), and processing outages will be:

$1=$ potentially large problems

$2=$ potentially small problems

$3=$ no perceived problems or benefits

$4=$ potentially small benefits

$5=$ potentially large benefits

Comment: No anticipated effect on Savanna River pinch weld activities. 


\section{Rocky Flats Results}

\section{SUMMARY FINDINGS}

\section{EFFECT ON INTANGIBLES}

EFFECT ON PUBLIC RELATIONS

If the proposal is successfully implemented:

(Evaluation Criterion IV.A.1)

34. Relations between the DOE facility

and the local community will:

$1=$ worsen dramatically

$2=$ worsen marginally

$3=$ stay the same (not applicable)

$4=$ improve marginally

$5=$ improve dramatically

(Evaluation Criterion IV.A.2)

35. Relations between the DOE facility and state regulatory agencies will:

$1=$ worsen dramatically

$2=$ worsen marginally

3 = stay the same (not applicable)

$4=$ improve marginally

$5=$ improve dramatically

(Evaluation Criterion IV.A.3)

36. Relations between the DOE facility and federal regulatory agencies will:

$1=$ worsen dramatically

$2=$ worsen marginally

$3=$ stay the saine (not applicable)

$4=$ improve marginally

$5=$ improve dramatically 


\section{Rocky Flats Results}

\section{SUMMARY FINDINGS}

\section{EFFECT ON INTANGIBLES}

EFFECT ON PUBLIC RELATIONS (Continued)

If the proposal is successfully implemented:

(Evaluation Criterion IV.A.4)

37. Relations between the DOE facility

$12(3) 5$ and the Congress will:

$$
\begin{aligned}
& 1=\text { worsen dramatically } \\
& 2=\text { worsen marginally } \\
& 3=\text { stay the same (not applicable) } \\
& 4=\text { improve marginally } \\
& 5=\text { improve dramatically }
\end{aligned}
$$

Comment: No measurable im; rovement in public relations. Acid overflow problem will be removed but this is a very minor improvement. 


\section{Rocky Fluts Results}

\section{SUMMARY FINDINGS}

\section{EFFECT ON INTANGIBLES}

EFFECT ON MANAGEMENT EFFECTIVENESS

If the proposal is successfully implemented:

(Evaluation Criterion IV.B.1)

38. The ability of the DOE facility to perform planning, waste monitoring, and reporting activities will:

$1=$ decrease significantly

$2=$ decrease slightly

$3=$ stay the same (not applicable)

$4=$ increase slightly

$5=$ increase significantly

Comment: No more hazardous waste in Building 460, reduction in staff management, building permits, etc.

(Evaluation Criterion IV.B.2)

39. The ability of the DOE facility to allocate costs to specific budget items (i.e., cost accountability) will:

$1=$ decrease significantly

$2=$ decrease slightly

$3=$ stay the same (not applicable)

$4=$ increase slightly

$5=$ increase significantly

Comment: N/A. 


\section{Rocky Flats Results \\ SUMMARY FINDINGS \\ EFFECT ON INTANGIBLES \\ EFFECT ON MANAGEMENT EFFECTIVENESS (Continued)}

If the proposal is successfully implemented:

(Evaluation Criterion IV.B.3)

4(). The ability of the DOE facility to respond favorably to periodic

inspecticns and assessments will:

$1=$ decrease significantly

$2=$ decrease slightly

$3=$ stay the same (not applicable)

$4=$ increase slightly

$5=$ increase significantly

Comment: No longer ship hazardous acid waste to hot side of plant. 


\section{Rocky Flats Results}

\section{SUMMARY FINDINGS}

TECHNICAL RISK

LIKELIHOOD OF SUCCESS

(Evaluation Criterion V.A.1)

41. To what extent does the successful

outcome of the proposal depend on

technological advances or

breakthroughs?

$1=$ significant advances required

$2=$ undemonstrated but some engineering principles understood

$3=$ undemonstrated but engineering principles well understood

$4=$ basic concept demonstrated elsewhere

$5=$ thoroughly demonstrated in similar applications

Comment: Confirmatory tests must be performed, but principles are clear. 
Rocky Flats Results

SUMMARY FINDINGS

TECHNICAL RISK

LIKELIHOOD OF SUCCESS (Continued)

(Evaluation Criterion V.A.2)

42. To what extent does the successful

outcome of the proposal depend on the

timely avallability of key personnel

and facilities?

$1=$ availability of personnel and facility resources highly uncertain

$2=$ availability of personnel and facility resources uncertain

$3=$ personnel and facility resources probably available

$4=$ personnel and facility resources most likely available

$5=$ highly certain that personnel and facility resources will be available

Comment: People and facilities will be available. 
Rocky Flats Results

SUMMARY FINDINGS

TECHNICAL RISK

RESEARCH AND DEVELOHMEN'T PAYOFF

If the proporal is successfully implemented:

(Evaluation Criterion V.B.1)

43. Will the research and development insights gained from this proposal be

1 (2) $3 \begin{array}{lll}3 & 4 & 5\end{array}$ applicable to other activities within

DOE?

$1=$ not appliciable

$2=$ remotely applicable

$3=$ slightly applicable

$4=$ moderately applicable

$5=$ highly applicable

Comment: No perceived other uses at this time.

(Evaluation Criterion V.B.2)

44. Will the research and development insights gained from this proposal be applicable to commercial industry?

$1=$ not applicable

$2=$ remotely applicable

$3=$ slightly applicable

$4=$ moderately applicable

$5=$ highly applicable

Comment: No perceived other uses at this time. Babcock \& Wilcox can also benefit in some bottle applications. 


\section{Rocky Flats Results}

\section{SUMMARY FINDINGS}

\section{TECHNICAL, RISK} CONSEQUENCE OF FAILURE

Assuming that the proposal is implemented but fails unexpectedly at a later date:

\section{(Evaluation Criterion V.C.1.a)}

45. The level of resources that would be required to analyze the failure, implement a fix, verify the change, and repair/replace existing products, assuming an average scenario, would be:

$$
\begin{aligned}
& 1=\text { extremely high } \\
& 2=\text { high } \\
& 3=\text { moderate } \\
& 4=\text { small } \\
& 5=\text { very small }
\end{aligned}
$$

Comment: Failure in SLS would demand recall. Expertise in place to reinstate old, accepted acid rinse methods. 
Rocky Flats Results

SUMMARY FINDINGS

TECHNICAL RISK

CONSEQUENCE OF FAILURE (Continued)

Assuming that the proposal is implemented but fails unexpectedly at a later cate:

(Evaluation Criterion V.C.1.b)

46. The level of resources that would be required to analyze the failure, implement a fix, verify the change, and repair/replace existing products, assuming a severe scenario, would be:

$1=$ estremely high

$2=$ high

$3=$ moderate

$4=$ small

$5=$ very small

Comment: Know-how in place to analyze and repair failures. Potenstally lange costs to decontaminate affected areas if in submarine.

(Evaluation Criterion V.C.2.a)

47. The level of production disruption that would occur while the failure is being remedied, assuming an average scenario, would be:

$1=$ extremely severe $(>3$ years $)$

$2=$ severe $(1$ to 3 years $)$

$3=$ large $(6$ months to 1 year)

$4=$ moderate ( 3 to 6 months)

$5=\operatorname{small}(<3$ months $)$

Comment: Existing acid rinse could be reinstated quickly. 


\section{Rocky Flats Results}

\section{SUMMARY FINDINGS}

'TECHNICAL RISK

CONSEQUENCE OF FAILURE (Continued)

Assuming that the proposal is implemented but fails unexpectedly at a later clate:

(Evaluation Criterion V.C.2.b)

48. The level of production disruption that would occur while the failure is being remedied, assuming a severe scenario, would be:

$1=$ extremely severe $(>3$ years $)$

$2=$ severe ( 1 to 3 years)

$3=$ large $(6$ months to 1 year $)$

$4=$ moclerite $(3$ to 6 months $)$

$5=$ small $(<3$ months $)$

Comment: Existing acid rinse conld be reinstaned quickly; investigation would most likely be major activity.

(Evaluation Criterion V.C.3.a)

49. The effect that the failure would have on product quality, assuming an average scenario, would be:

$1=$ extreme negative effect

$2=$ large negative effect

$3=$ moderate negative effect

$4=$ small negative effect

$5=\mathrm{no}$ effect

Cormment: Failures detected during SLS would call for lange investigation, possible recall. Limited-life components (LLCS) relatively easy to replace. Losis of weapon performance depends on extent of problem. 
$\underline{\text { Rocky Flats Results }}$

SUMMARY FINDINGS

TECHNICAL RISK

CONSEQUEN 'CE OF FAILURE (Continued)

Assuming that the proposal is implemented but fails unexpectedly at a later date:

(Evaluation Criterion V.C.3.b)

50. The effect that the failure would

1 (2) $3 \quad 4 \quad 5$

have on product quality, assuming a

severe scenario, would be:

$1=$ extreme negative effect

$2=$ large negative effect

$3=$ moderate negative effect

$4=$ small negative effect

$5=$ no effect

Comment: Large-scale tritium leakage of many different types of bottles would involve extensive replacements. Most weapons potentially affected. LLC components relatively easy to replace. Tritium loss would degrade weapon performance. 


\section{APPENDIX D}

Summary Findings for Pinellas Plant Test Case Study

D-1/D-2 
Pinellas Results

\section{SUMMARY FINDINGS}

\section{ECONOMIC FEASIBILITY \\ COST CONSIDERATIONS}

(Evaluation Criterion I.A.1)

1. The net present value (NPV) of all

life cycle costs associated with the

proposal is:

$1=$ large, negative $(<-\$ 500,000)$

$2=$ negative $(-\$ 1000$ to $-\$ 500,000)$

$z=$ approximately zero (break even)

$4=$ positive $(\$ 1000$ to $\$ 500,000)$

$5=$ large, positive $(>\$ 500,000)$

Comment: NPV@10\%=-\$543K

(a) $8 \%=-\$ 572 K$

@ $6 \%=-\$ 605 K$

(See NPV diagram given in Figure 5-3. Note that many of the cost savings attributable to the proposal could not be identified for the test case.)

(Evaluation Criterion I.A.2.a)

2. The total, discounted cost of the implementation phase of the proposal will be:

$$
\begin{aligned}
& 1=\text { very high }(>\$ 10,000,000) \\
& 2=\text { high }(\$ 5,000,000 \text { to } \$ 10,000,000) \\
& 3=\text { moderate }(\$ 1,000,000 \text { to } \$ 5,000,000) \\
& 4=\text { low }(\$ 500,000 \text { to } \$ 1,000,000) \\
& 5=\text { very low }(<\$ 500,000)
\end{aligned}
$$

Comment: NPV@10\% $=-\$ 543 \mathrm{~K}$

(a) $8 \%=-\$ 572 K$

(a) $6 \%=-\$ 605 K$

(See NPV diagram given in Figure 5-3. These discounted figures represent the $N P V$ of all costs that will be experienced before the proposal is complete and successfully implemented.) 
Pinellas Results

SUMMARY FINDINGS

ECONOMIC FEASIBILITY

COST CONSIDERA'TIONS (Continued)

(Evaluation Criterion I.A.2.b)

3. The effect the proposal will have on

the annual operating costs to DOE will be:

12 (3) 45

$1=$ large losses $(<-\$ 50,000 /$ year $)$

$2=$ moderate losses $(-\$ 1000$ to $-\$ 50,000 /$ year $)$

$3=$ approximately $\$ 0 /$ year

$4=$ moderate savings ( $\$ 1000$ to $\$ 50,000 /$ year)

$5=$ large savings $(>\$ 50,000 /$ year $)$

Comment: Zero -. no noted operarional cost savings. Liability/worker productivity issues not quantified. (See NPV diagram given in Figure 5-3. Note that many of the cost savings attributable to this proposal could not be identified for the test case.) 
Pinellas Results

\section{SUMMARY FINDINGS}

ECONOMIC FEASIBILITY

TIME CONSIDERATIONS

(Evaluation Criterion I.B.1)

4. The total length of time required to

1 (2) 345 complete all phases of the proposal

will be:

$$
\begin{aligned}
& 1=\text { greater than } 10 \text { years } \\
& 2=6 \text { to } 10 \text { years } \\
& 3=3 \text { to } 6 \text { years } \\
& 4=1 \text { to } 3 \text { years } \\
& 5=\text { less than } 1 \text { year }
\end{aligned}
$$

Comment: 6 years, 8 months (1/84 - 8/90).

(See NPV timeline given in Figure 5-3)

(Evaluation Criterion I.B.2.a)

5. The length of time required to

perform research, development, and

(1) $\begin{array}{llll}2 & 3 & 4 & 5\end{array}$ testing activities will be:

$$
\begin{aligned}
& 1=\text { greater than } 6 \text { years } \\
& 2=4 \text { to } 6 \text { years } \\
& 3=2 \text { to } 4 \text { years } \\
& 4=1 \text { to } 2 \text { years } \\
& 5=\text { less than } 1 \text { year }
\end{aligned}
$$

Comment: 6 years, 8 months (1/84 - 8/90). (See NPV timeline given in Figure 5-3) 


\section{Pinellas Results \\ SUMMARY FINDINGS \\ ECONOMIC FEASIBILITY \\ TIME CONSIDERATIONS (Continued)}

(Evaluation Criterion I.B.2.b)

6. The length of time required to perform verification testing to certify products from the modified manufacturing line will be:

$1=$ greater than 6 years

$2=4$ to 6 years

$3=2$ to 4 years

$4=1$ to 2 years

$5=$ less than 1 year

Comment: No verification of new products from manufacturing line; no shell life storage program (SLS). (See NPV timeline given in Figure 5-3)

(Evaluation Criterion I.B.2.c)

7. The length of time required to perform facility modifications to accomodate the proposal will be:

$1=$ greater than 2 years

$2=1$ to 2 years

$3=6$ months to 1 year

$4=3$ to 6 months

$5=$ less than 3 months

Comment: Modifications are ongoing; not on critical path. 
Pinellas Results

\section{SUMMARY FINDINGS}

\section{EFFECT ON ENVIRONMENTAL, SAFETY, AND HEALTH ISSUES EFFECT ON HAZARDOUS MATERIAL AND WASTE QUANTITY}

If the proposal is successfully implemented:

(Evaluation Criterion II.A.1.a)

8. The rate at which the specific process generates hazardous waste will:

$1=$ increase significantly $(>25 \%)$

$2=$ increase moderately (5\% to $25 \%)$

$3=$ stay the same

$4=$ decrease moderately ( $5 \%$ to $25 \%)$

$5=$ decrease significantly $(>25 \%)$

Comment: Process volume/waste will be the same, handled in same way.

(Evaluation Criterion II.A.1.b)

9. The rate at which the entire facility

12 (3) 45 generates hazardous waste will:

$1=$ increase significantly $(>25 \%)$

$2=$ increase moderately ( $5 \%$ to $25 \%)$

$3=$ stay the same

$4=$ decrease moderately $(5 \%$ to $25 \%)$

$5=$ decrease significantly $(>25 \%)$

Comment: No effect; waste volume produced in process will remain the same. 
Pinellas Results

\section{SUMMARY FINDINGS}

EFFECT ON ENVIRONMENTAL, SAFETY, AND HEALTH ISSUES EFFECT ON HAZARDOUS MATERIAL AND WASTE QUANTITY (Continued)

If the proposal is successfully implemented:

(Evaluation Criterion II.A.2.a)

10. The rate at which the specific

process consumes hazardous material

will:

$1=$ increase significantly $(>25 \%)$

$2=$ increase moderately ( $5 \%$ to $25 \%)$

$3=$ stay the same

$4=$ decrease moderately ( $5 \%$ to $25 \%)$

$5=$ decrease significantly $(>25 \%)$

Comment: Sam. amount used with Ethacure (100 gallyear).

(Evaluation Criterion II.A.2.b)

11. The rate at which the entire facility consumes hazardous material will:

$1=$ increase significantly $(>25 \%)$

$2=$ increase moderately ( $5 \%$ to $25 \%$ )

$3=$ stay the same

$4=$ decrease moderately (5\% to $25 \%)$

$5=$ decrease significantly $(>25 \%)$

Comment: Same amount of hazmat used at plant. 
Pinellas Results

\section{SUMMARY FINDINGS}

EFFECT ON ENVIRONMENTAL, SAFETY, AND HEALTH ISSUES EFFECT ON HAZARDOUS MATERIAL AND WASTE QUANTITY (Continued)

If the proposal is successfully implemented:

(Evaluation Criterion II.A.3)

12. The rate at which hazardous waste must be stored on-site at the facility will:

$1=$ increase significantly

$2=$ increase slightly

$3=$ stay the same (not applicable)

$4=$ decrease slightly

$5=$ decrease significantly

Comment: No effect on hazmat/waste storage.
12 (3) $4 \quad 5$ 
Pinellas Results

\section{SUMMARY FINDINGS}

\section{EFFECT ON ENVIRONMENTAL, SAFETY, AND HEALTH ISSUES EFFECT ON HUMAN EXPOSURE}

If the proposal is suocessfully implemented:

(Evaluation Criterion II.B.1.a)

13. The number of workers exposed to hazardous material and waste during

normal operations will:

$1=$ increase significantly

$2=$ increase slightly

$3=$ stay the same (not applicable)

$4=$ decrease slightly

$5=$ decrease significantly

Conment: Same process; autodispensing unit could be used with Shell Z or Ethacure.

(Evaluation Criterion II.B.1.b)

14. The number of workers exposed to hazardous material and waste during postulated accident coriditions will:

$1=$ increase significantly

$2=$ increase slightly

$3=$ stay the same (not applicable)

$4=$ decrease slightly

$5=$ decrease significantly

Comment: Same; no difference in exposure pathways. 
Pinellas Results

\section{SUMMARY FINDINGS}

\section{EFFECT ON ENVIRONMENTAL, SAFETY, AND HEALTH ISSUES EFFECT ON HUMAN EXPOSURE (Continued)}

If the proposal is successfully implemented:

(Evaluation Criterion II.B.1.c)

15. The level of worker contact to hazardous material and waste couring the implementation phase of the proposal will result in:

$1=$ extreme exposure

$2=$ large exposure

$3=$ moderate exposure

$4=$ small exposure

$5=$ essentially no exposure

Comment: No exposure during substitution of Ethacure for Shell Z. No exposure during equipment modification.

(Evaluation Criterion II.B.2.a)

16. The level of public exposure to hazardous material and waste during normal operations will:

$$
\begin{aligned}
& 1=\text { increase significantly } \\
& 2=\text { increase slightly } \\
& 3=\text { stay the same (not applicable) } \\
& 4=\text { decrease slightly } \\
& 5=\text { decrease significantly }
\end{aligned}
$$

Comment: No appreciable public risk in normal operations; no change. 
$\underline{\text { Pinellas Results }}$

\section{SUMMARY FINDINGS}

\section{EFFECT ON ENVIRONMENTAL, SAFETY, AND HEALTH ISSUES EFFECT ON HUMAN EXPOSURE (Continued)}

If the proposal is successfully implemented:

(Evaluation Criterion II.B.2.b)

17. The level of public exposure to hazardous material and waste during postulated accident conditions will:

$$
\begin{aligned}
& 1=\text { increase significantly } \\
& 2=\text { increase slightly } \\
& 3=\text { stay the same (not applicable) } \\
& 4=\text { decrease slightly } \\
& 5=\text { decrease significantly }
\end{aligned}
$$

Comment: No appreciable public risk under accident condition; no change. 
Pinellas Results

SUMMARY FINDINGS

EFFECT ON ENVIRONMENTAL, SAFETY, AND HEALTH ISSUES

EFFECT ON MATERIAL HAZARD LEVEL

If the proposal is successfully implemented:

(Evaluation Criterion II.C.1)

18. The overall texicity of the hazardous

123 (4) 5

material(s) used in the process(es)

will:

$1=$ increase significantly

$2=$ increase slightly

$3=$ stay the same (not applicable)

$4=$ decrease slightly

$5=$ decrease significantly

Comment: Ethacure lethal dose slightly less; long-term lethality slightly improved.

(Evaluation Criterion II.C.2)

19. The overall carcinogenicity of the

123 (4) 5 hazardous material(s) used in the

process(es) will:

$1=$ increase significantly

$2=$ increase slightly

$3=$ stay the same (not applicable)

$4=$ decrease slightly

$5=$ decrease significantly

Comment: Ethacure may be listed as a potential carcinogen by Occupational Safety and Health Administration (OSHA); long-term tests show no cancer to date (tests not over yet). 


\section{Pinellas Results}

\section{SUMMARY FINDINGS}

\section{EFFECT ON ENIVIRONMENTAL, SAFETY, AND HEALTH ISSUES EFFECT ON MATFRIAL HAZARD LEVEL (Continued)}

If the proposal is successfully implemented:

(Evaluation Criterion II.C.3)

20. The overall mutagenicity of the hazardous matrial(s) used in the process(es) will:

$1=$ increase significantly

$2=$ increase slightly

$3=$ stay the same (not applicable)

$4=$ decrease slightly

$5=$ decrease significantly

Comment: Mutagenicity may improve; tests inconclusive to date.

(Evaluation Criterion II.C.4)

21. The overall flammability/explosivi's characteristics of the hazardous material(s) used in the processíes) will:

$1=$ increase significantly

$2=$ increase slightly

$3=$ stay the same (not applicable)

$4=$ decrea.e slightly

$5=$ decrease significantly

Comment: Flammability characteriatics will not change.
12 (3) $4 \quad 5$

12 (3) 45 
Pinellas Results

\section{SUMMARY FINDINGS}

\section{EFFECT ON ENVIRONMENTAL, SAFETY, AND HEALTH ISSUES EFFECT ON MATERIAL HAZARD LEVEL (Continued)}

If the proposal is successfully implemented:

(Evaluation Criterion II.C.5)

22. The overall corrosivity of the hazardous material(s) used in the process(es) will:

$1=$ increase significantly

$2=$ increase slightly

$3=$ stay the same (not applicable)

$4=$ decrease slightly

$5=$ decrease sigrificantly

Comment: Corrosivity characteristics will not change.
12345

(Evaluation Criterion II.C.6)

23. The overall ?ctivity level of the hazardous material(s) used in the process(es) will:

$1=$ increase significantly

$2=$ increase slightly

$3=$ stay the same (not applicable)

$4=$ decrease slightly

$5=$ decrease significantly

Comment: N/A. 
$\underline{\text { Pinellas Results }}$

\section{SUMMARY FINDINGS}

\section{EFFECT ON OPERATIONAL REQLIREMENTS EFFECT ON PRODUCT QUALITY}

If the proposal is successfully implemented:

(Evaluation Criterion III.A.1)

24. The reliability of the ultimate prociuct(s) provided by the DOE facilities involved in the proposal

will:

$1=$ decrease significantly

$2=$ decrease slightly

$3=$ stay the same (not applicable)

$4=$ increase slightly

$5=$ increase significantly

Comment: Offgassing not a big factor for Ethacure. No other noted potential issues.

(Evaluation Criterion III.A.2)

25. The safety of the ultimate product(s) provided by the DOE facilities involved in the proposal will:

$1=$ decrease significantly

$2=$ decrease slightly

$3=$ stay the same (not applicable)

$4=$ increase slightly

$5=$ increase significantly

Comment: No effect on weapon safety. 
$\underline{\text { Pinellas Results }}$

SUMMARY FINDINGS

EFFECT ON OPERATIONAL REQUIREMENTS

EFFECT ON PRODUCT QUALITY (Continued)

If the proposal is successfully implemented:

(Evaluation Criterion III.A.3)

26. The testability of the ultimate 12 (3) 45 product(s) provided by the DOE facilities involved in the proposal will:

$1=$ decrease significantly

$2=$ decrease slightly

$3=$ stay the same (not applicable)

$4=$ increase slightly

$5=$ increase significantly

Comment: Voltage tests used to check product. Arming, fusing, and firing systems inprocess/storage could be tested.

(Evaluation Criterion III.A.4)

27. The maintainability of the ultimate

12 (3) 45 product(s) provided by the DOE facilities involved in the proposal will:

$1=$ decrease significantly

$2=$ decrease slightly

$3=$ stay the same (not applicable)

$4=$ increase slightly

$5=$ increase significantly

Comment: N/A; magnetic parts not maintained (some neutron generators are). 
Pinellas Results

\section{SUMMARY FINDINGS}

\section{EFFECT ON OPERATIONAL REQUIREMENTS \\ EFFECT ON PROCESSING CHARACTERISTICS}

If the proposal is successfully implemented:

(Evaluation Criterion III.B.1)

28. The operating yield of the process(es) involved in the proposal

will:

$1=$ decrease significantly

$2=$ decrease slightly

$3=$ stay the same (not applicable)

$4=$ increase slightly

$5=$ increase significantly

Comment: No effect in process yield if Shell $Z$ or Ethacure.

(Evaluation Criterion III.B.2)

29. The operating capacity of the process(es) involved in the proposal will:

$1=$ decrease significantly

$2=$ decrease slightly

$3=$ stay the same (not applicable)

$4=$ increase slightly

$5=$ increase significantly

Comment: Capacity may increase due to worker confidence. 
Pinellas Results

SUMMARY FINDINGS

EFFECT ON OPERATIONAL REQUIREMENTS

EFFECT ON PROCESSING CHARACTERISTICS (Continued)

If the proposal is successfully implemented:

(Evaluation Criterion III.B.3)

30. The operating availability of the process(es) involved in the proposal

12 (3) 4

will:

$1=$ decrease significantly

$2=$ decrease slightly

$3=$ stay the same (not applicable)

$4=$ increase slightly

$5=$ increase significantly

Comment: No effect on availability.

(Evaluation Criterion III.B.4)

31. The operating safety of the process(es) involved in the proposal

12 (3) 45 will:

$1=$ decrease significantly

$2=$ decrease slightly

$3=$ stay the same (not applicable)

$4=$ increase slightly

$5=$ increase significantly

Comment: Safety of process (other than reduction in material hazard level) will remain unchanged. 


\section{Pinellas Results \\ SUMMARY FINDINGS \\ EFFECT ON OPERATIONAL REQUIREMENTS \\ EFFECT ON PROCESSING CHARACTERISTICS (Continued)}

If the proposal is successfully implemented:

(Evaluation Criterion III.B.5)

32. How long must the process(es) be

halted to implement the proposal?

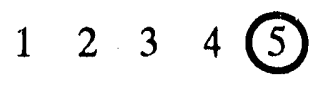

$1=$ extreme outage ( $>6$ months)

$2=$ major outage ( 3 to 6 months)

$3=$ moderate outage ( 1 to 3 months)

$4=$ minor outage $(<1$ month $)$

$5=$ not at all

Comment: Parrallel effort ongoing for implementation (automated mixing). Approximately 0 time delay for implementation once test results look good.

(Evaluation Criterion III.B.6)

33. The effect of the change on other processes at the plant and other DOE facilities with respect to issues such as compatibility, burden shifting (waste management responsibilities), and processing outages will be:

$1=$ potentially large problems

$2=$ potentially small problems

$3=$ no perceived problems or benefits

$4=$ potentially small benefits

$5=$ potentially large benefits

Comment: Offgassing studies look good.

Kansas City currently studying assembly integration issues with Ethacure. 


\section{Pinellas Results \\ SUMMARY FINDINGS \\ EFFECT ON INTANGIBLES \\ EFFECT ON PUBLIC RELATIONS}

If the proposal is successfully implemented:

(Evaluation Criterion IV.A.1)

34. Relations between the DOE facility

and the local community will:

12 (3) 45

$1=$ worsen dramatically

$2=$ worsen marginally

$3=$ stay the same (not applicable)

$4=$ improve marginally

$5=$ improve dramaticent:y

Comment: No effect.

(Evaluation Criterion IV.A.2)

35. Relations between the DOE facility and state regulatory agencies will:

$1=$ worsen dramatically

$2=$ worsen marginally

$3=$ stay the same (not applicable)

$4=$ improve marginally

$5=$ improve dramatically

Comment: No effect. 


\section{Pinellas Results}

\section{SUMMARY FINDINGS}

\section{EFFECT ON INTANGIBLES}

EFFECT ON PUBLIC RELATIONS (Continued)

If the proposal is successfully implemented:

(Evaluation Criterion IV.A.3)

36. Relations between the DOE facility

$12(3) 5$

and federal regulatory agencies will:

$1=$ worsen dramatically

$2=$ worsen marginally

$3=$ stay the same (not applicable)

$4=$ improve marginally

$5=$ improve dramatically

Comment: Come inlo compliance with OSHA.

(Evaluation Criterion IV.A.4)

37. Relations between the DOE facility and the Congress will:

$1=$ worsen dramatically

$2=$ worsen marginally

$3=$ stay the same (not applicable)

$4=$ improve marginally

$5=$ improve dramatically

Comment: No effect. 
Pinellas Results

\section{SUMMARY F'INDINGS}

EFFECT ON INTANGIBLES

EFFECT ON MANAGEMENT EFFECTIVENESS

If the proposal is successfully implemented:

(Evaluation Criterion IV.B.1)

38. The ability of the DOE facility to

12 (3) 4 perform planning, waste monitoring, and reporting activities will:

$1=$ decrease significantly

$2=$ decrease slightly

$3=$ stay the same (not applicable)

$4=$ increase slightly

$5=$ increase significantly

Comment: No appreciable effect on these activities.

(Evaluation Criterion IV.B.2)

39. The ability of the DOE facility to allocate costs to specific budget items (i.e., cost accountability)

will:

$1=$ decrease significantly

$2=$ decrease slightly

$3=$ stay the same (not applicable)

$4=$ increase slightly

$5=$ increase significantly

Comment: $N / A$. 


\section{Pinellas Results \\ SUMMARY FINDINGS \\ EFFEC,T ON INTANGIBLES \\ EFFECT ON MANAGEMENT EFFECTIVENESS (Continued)}

If the proposal is successfully implemented:

(Evaluation Criterion IV.B.3)

40. The ability of the DOE facility to

123 (4) 5

respond favorably to perindic

inspections and assessments will:

$1=$ decrease significantly

$2=$ decrease slightly

$3=$ stay the same (not applicable)

$4=$ increase slightly

$5=$ increase significantly

Comment: If the human suspect carcinogen is eliminated, OSHA inspection problems will subside. 
Pinellas Results

\section{SUMMARY FINDINGS}

TECHNICAL RISK

LIKELIHOOD OF SUCCESS

(Evaluation Criterion V.A.1)

41. To what extent does the successful

12 (3) 45 outcome of the proposal depend on technological advances or breakthroughs?

$$
\begin{aligned}
& 1=\text { significant advances required } \\
& 2=\text { undemonstrated but some } \\
& \text { engineering } \mathrm{p} \text {. ciples } \\
& \text { understood } \\
& 3=\text { undemonstrated but engineering } \\
& \text { principles well understood } \\
& 4=\text { basic concept demonstrated } \\
& \text { elsewhere } \\
& 5=\text { thoroughly demonstrated in } \\
& \text { similar applications }
\end{aligned}
$$

Comment: Demoristrated for neutron generators. No long-term testing results available. Chemical research staff highly confident. Some problems using neutron generator recipe for magnetics. 
Pinellas Results

\section{SUMMARY FINDINGS}

\section{TECHNICAL RISK \\ LIKELIHOOD OF SUCCESS (Continued)}

\section{(Evaluation Criterion V.A.2)}

42. To what extent does the successful outcome of the proposal depend on the timely availability of key personnel and facilities?

$1=$ availability of personnel and facility resources highly uncertain

$2=$ availability of personnel and facility resources uncertain

$3=$ personnel and facility resources probably available

$4=$ personnel and facility resources most likely available

$5=$ highly certain that personnel and facility resources will be available

Comment: People and facilities will be available. 


\section{Pinellas Results}

\section{SUMMARY FINDINGS}

\section{TECHNICAL RISK RESEARCH AND DEVELOPMENT PAYOFF}

If the proposal is successfully implemented:

(Evaluation Criterion V.B.1)

43. Will the research and development insights gained from this proposal be applicable to other activities within DOE?

$1=$ not applicable

$\hat{2}=$ remotely applicable

$3=$ slightly applicable

$4=$ moderately applicable

$5=$ highly applicable

Commen:: Shell $Z$ is also used at Kansas City plant, maybe Mound plant as well. Could eliminate all Shell $Z$ in future. However, not much Shell $Z$ used in DOE complex.

(Evaluation Criterion V.B.2)

44. Will the research and development insights gained from this proposal be applicable to commercial industry?

$$
\begin{aligned}
& 1=\text { not applizable } \\
& 2=\text { reinotely applicable } \\
& 3=\text { slightly applicable } \\
& 4=\text { moderately applicable } \\
& 5=\text { highly applicable }
\end{aligned}
$$

Comment: Uncertain of commer 7 l uses of Shell Z. Possibly some commercial application. 


\section{Pinellas Results}

\section{SUMMARY FINDINGS}

TECHNICAL RISK CONSFQUENCE OF FAILURE

Assuming that the proposal is implemented but fails unexpectedly at a later date:

(Evaluation Criterion V.C.1.a)

45. The level of resources that would be

1 (2) 345 required to analyze the failure, implement a fix, verify the change, and repair/replace existing products, assuming an average scenario, would be:

$1=$ extremely high

$2=$ high

$3=$ noderate

$4=$ small

$5=$ very small

Comment: Any failures found in stockpile would be costly. All affected weapons must be sent to Pantex for disassembly. Many parts in many weapons use Shell Z/Ethacure-potted components. 
Pinellas Results

\section{SUMMARY FINDINGS}

TECHNICAL RISK

CONSEQUENCE OF FAILURE (Continued)

Assuming that the proposal is implemented but fails unexpectedly at a later date:

(Evaluation Criterion V.C.1.b)

46. The level of resources that would be

(1) $2 \begin{array}{llll}2 & 3 & 4 & 5\end{array}$ required to analyze the failure, implement a fix, verify the change, and repair/replace existing products, assuming a severe scenario, would be:

$1=$ extremely high

$2=$ high

$3=$ moderate

$4=$ small

$5=$ very small

Comment: Repairing existing weapons would require recall to Pantex and disassembly of arming, fusing, and firing systems. If Siic!l $Z$ is not available and Ethacure cannot be reworked, new technology must be developed.

(Evaluation Criterion V.C.2.a)

47. The level of production disruption that would occur while the failure is being remedied, assuming an average scenario, would be:

$1=$ extremely severe $(>3$ years $)$

$2=$ severe ( 1 to 3 years)

$3=$ large ( 6 months to 1 year)

$4=$ moderate ( 3 to 6 months)

$5=$ small $(<3$ months $)$

Comment: 4 months if caught early on: John Foley. 
Pinellas Results

SUMMARY FINDINGS

TECHNICAL RISK

CONSEQUENCE OF FAILURE (Continued)

Assuming that the proposal is implemented but fails unexpectedly at a later date:

(Evaluation Criterion V.C.2.b)

48. The level of production disruption that would occur while the failure is

(1) $\begin{array}{llll}2 & 3 & 4 & 5\end{array}$ being remedied, assuming a severe scenario, would be:

$1=$ extremely severe $(>3$ years $)$

$2=$ severe (1 to 3 years)

$3=$ large $(6$ months to 1 year $)$

$4=$ moderate ( 3 to 6 months)

$5=$ small $(<3$ months $)$

Comment: If Shell $Z$ not available and rework of Ethacure not possible, approximately 5 years to develop next technology: Barbara Wells.

(Evaluation Criterion V.C.3.a)

49. The effect that the failure would

1 (2) $3 \quad 4 \quad 5$ have on product quality, assuming an

average scenario, would be:

$1=$ extreme negative effect

$2=$ large negative effect

$3=$ moderate negative effect

$4=$ small negative effect

$5=$ no effect

Comment: Small safety impact. Potentially high reliability impact, many parts affected. 
Pinellas Results

\section{SUMMARY FINDINGS}

TECHNICAL RISK

CONSEQUENCE OF FAILURE (Continued)

Assuming that the proposal is implemented but fails unexpectedly at a later date:

(Evaluation Criterion V.C.3.b)

50. The effect that the failure would

(1) $\begin{array}{lllll}2 & 3 & 4 & 5\end{array}$ have on product quality, assuming a severe scenario, would be:

$1=$ extreme negative effect

$2=$ large negative effect

$3=$ moderate negative effect

$4=$ small negative effect

$5=$ no efiect

Comment: Weapon safety may be reduced. Large effect on weapon reliability; functionality severely impaired if multiple components fail due to Ethacure problems. 

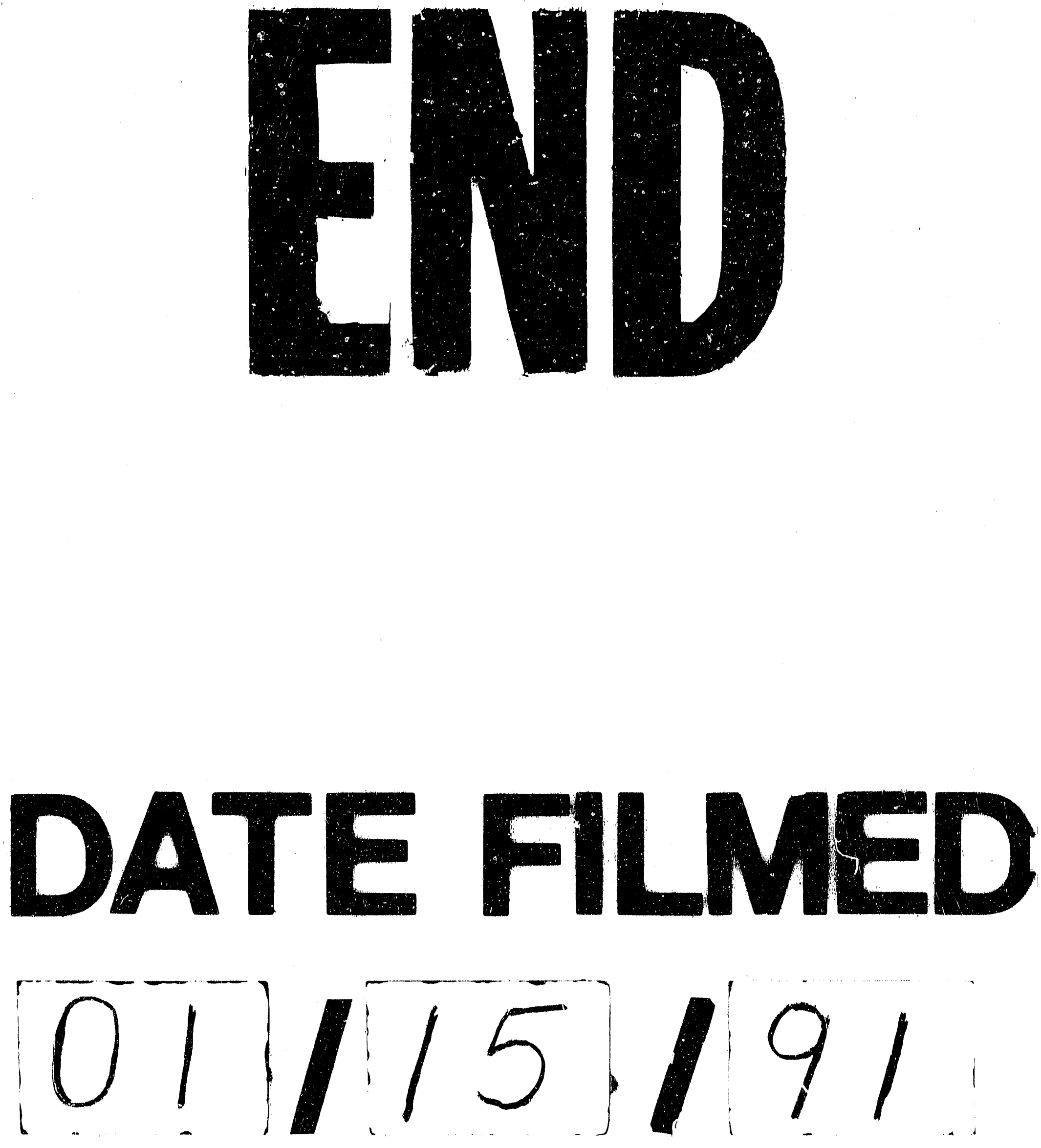
